\title{
Cooperative Research in C1 Chemistry
}

Six month-report on research conducted from May 1, 2000 to October 30, 2000 DOE Cooperative Agreement No. DE-FC26-99FT40540

Prepared by the Consortium for Fossil Fuel Liquefaction Science

Gerald P. Huffman, Director

CFFLS / University of Kentucky

533 S. Limestone Street, Room 111

Lexington, KY 40506

Phone: (859) 257-4027

FAX: (859) 257-7215

E-mail: cffls@pop.uky.edu

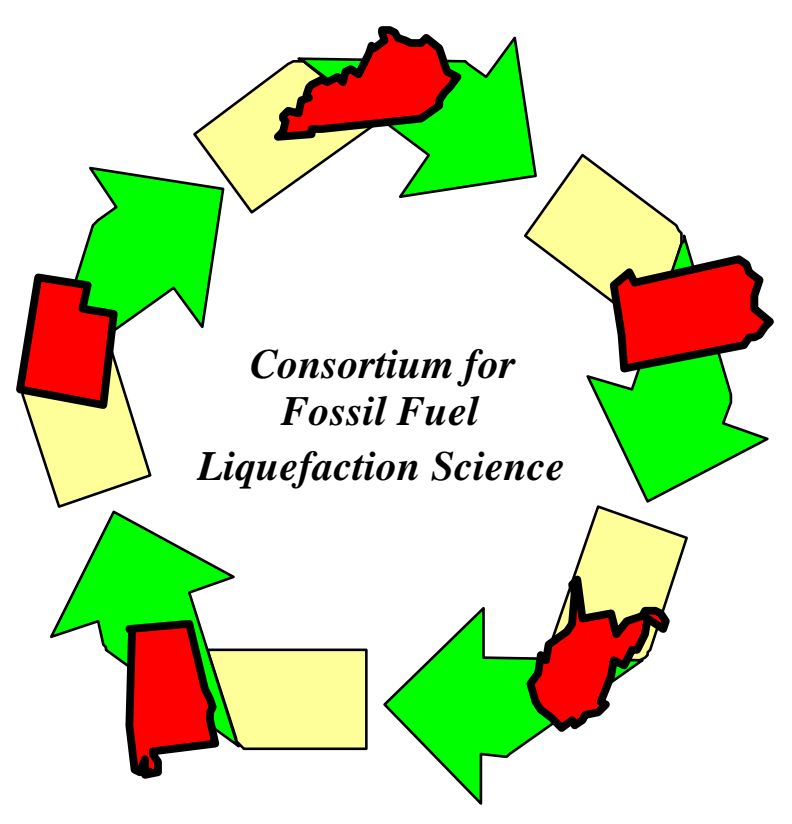

University of Kentucky West Virginia University University of Pittsburgh

University of Utah

Auburn University 


\section{DISCLAIMER}

This report was prepared as an account of work sponsored by an agency of the United States Government. Neither the United States Government nor any agency thereof, nor any of their employees, makes any warranty, express or implied, or assumes any legal liability or responsibility for the accuracy, completeness, or usefulness of any information, apparatus, product, or process disclosed, or represents that its use would not infringe privately owned rights. Reference herein to any specific commercial product, process, or service by trade name, trademark, manufacturer, or otherwise does not necessarily constitute or imply its endorsement, recommendation, or favoring by the United States Government or any agency thereof. The views and opinions of authors expressed herein do not necessarily state or reflect those of the United States Government or any agency thereof. 


\section{Table of Contents}

\begin{tabular}{|c|c|}
\hline Topic & Page \\
\hline Introduction & 3 \\
\hline Program Goals and First Year Accomplishments & 5 \\
\hline Fuels and Chemicals Via Fischer-Tropsch & 4 \\
\hline $\begin{array}{l}\text { Hydrogenation of F-T Products and Polyolefins to Environmentally Clean High } \\
\text { Cetane Diesel Fuels, Jet Fuels and Lube-based Oils }\end{array}$ & 7 \\
\hline Dialkyl Carbonates from Alcohols and CO & 13 \\
\hline Synthesis of Higher Carbon Ethers from Methanol and Olefins & 17 \\
\hline Higher Alcohol Synthesis from Methanol or Syngas & 20 \\
\hline Conversion of Synthesis Gas to Higher Ethers and Other Oxygenates & 23 \\
\hline $\begin{array}{l}\text { Supercritical Fluids as an Alternative Reaction Medium for Fischer-Tropsch } \\
\text { Synthesis }\end{array}$ & 31 \\
\hline Reforming of Natural Gas with Carbon Dioxide & 38 \\
\hline Hydrogen Production by Non-Oxidative Catalytic Decomposition of Methane & 41 \\
\hline In Situ Catalyst Characterization by XAFS Spectroscopy & 47 \\
\hline Diesel Engine Testing of Oxygenated Fuel Additives; Preliminary Test Results & 49 \\
\hline Analytical Characterization of Catalyst Structure and Product Distribution & 53 \\
\hline
\end{tabular}




\title{
Cooperative Research in C1 Chemistry
}

\author{
Prepared by the Consortium for Fossil Fuel Liquefaction Science
}

July 2000

\section{Introduction}

C1 chemistry refers to the conversion of simple carbon-containing materials that contain one carbon atom per molecule into valuable products. The feedstocks for $\mathrm{C} 1$ chemistry include natural gas, carbon dioxide, carbon monoxide, methanol and synthesis gas (a mixture of carbon monoxide and hydrogen). Synthesis gas, or syngas, is produced primarily by the reaction of natural gas, which is principally methane, with steam. It can also be produced by gasification of coal, petroleum coke, or biomass. The availability of syngas from coal gasification is expected to increase significantly in the future because of increasing development of integrated gasification combined cycle (IGCC) power generation.

Because of the abundance of remote natural gas, the advent of IGCC, and environmental advantages, $\mathrm{C} 1$ chemistry is expected to become a major area of interest for the transportation fuel and chemical industries in the relatively near future. The CFFLS will therefore perform a valuable national service by providing science and engineering graduates that are trained in this important area.

Syngas is the source of most hydrogen. Approximately 10 trillion standard cubic feet (SCF) of hydrogen are manufactured annually in the world. Most of this hydrogen is currently used for the production of ammonia and in a variety of refining and chemical operations. However, utilization of hydrogen in fuel cells is expected to grow significantly in the next century.

Syngas is also the feedstock for all methanol and Fischer-Tropsch plants. Currently, world consumption of methanol is over 25 million tons per year. There are many methanol plants in the U.S. and throughout the world. Methanol and oxygenated transportation fuel products play a significant role in the CFFLS C1 program. Currently, the only commercial Fischer-Tropsch plants are overseas, principally in South Africa (SASOL). However, new plants are being built or planned for a number of locations. One possible location for future FT plant development in the U.S. is in the Alaskan oil fields. 


\section{Program Goals and First Year Accomplishments}

The principal objectives of the CFFLS C1 research program are as follows:

D Develop technology for conversion of $\mathrm{C} 1$ source materials (natural gas, synthesis gas, carbon dioxide and monoxide, and methanol) into clean, high efficiency transportation fuel, especially diesel fuel.

$>$ Develop improved processes to convert natural gas into syngas.

$>$ Develop new processes for producing hydrogen from natural gas and other hydrocarbons.

A further general goal is to develop improved understanding of catalytic reaction mechanisms for all of these processes.

A brief summary of the principal accomplishments of the research program during its first year is given below.

$>$ Fischer-Tropsch fuels containing oxygen have been synthesized.

$>$ Higher ethers (C6-C8) have been synthesized from olefins, methanol and ethanol.

$>$ Dimethyl and diethyl carbonates have been produced from the reaction of methanol and carbon monoxide.

$>$ A small diesel engine has been set up to test the effects of these fuels, either alone or as additives, on particulate matter emissions and cetane level.

$>$ Nanoscale, binary, Fe-based catalysts have been shown to have significant catalytic activity for the decomposition of methane to produce pure hydrogen.

$>$ An environmentally safe catalyst for the hydroisomerization of straight-chain alkanes has been developed that may be useful for producing low pour point diesel fuel from F-T wax.

$>$ Work on $\mathrm{CO}_{2}$ reforming of methane to synthesis gas has been initiated.

$>$ The reaction of $\mathrm{CO}_{2}$ with ethylbenzene to produce styrene, which is a high volume, high value chemical, appears to a promising method of utilizing a greenhouse gas.

$>$ In situ measurement capability has been developed for several analytical techniques to allow determination of catalyst structures and product suites during $\mathrm{C} 1$ reactions.

The remainder of this report presents a brief summary of the work carried out on each project. 


\title{
Fuels and Chemicals Via Fischer-Tropsch
}

\author{
Irving Wender, J.W. Tierney and G.D. Holder, University of Pittsburgh
}

This task has been combined with Task II as given in our May 1, 2000 proposal. Task II in this proposal is: On the Effects of Added Oxygenated Compounds on Lowering Particle Matter Emissions from Diesel Fuels.

We had proposed, in Task II, to study a number of oxygenated compounds to be added to diesel fuel derived from petroleum and to determine their influence on both cetane number and the lowering of emissions. However, we have combined Tasks I and II since Dr. Bill Piel of the Oxygenate Analysis Project has furnished us with a comprehensive list of oxygenated compounds currently being surveyed as candidates for addition to petroleum low sulfur diesel fuels. We have, therefore, directed our efforts to obtain high cetane diesel fuels in the direction highlighted in our first proposed task, namely the preparation of oxygenated diesel fuel via the Fischer-Tropsch (F-T) reaction. This approach does not use added oxygenated compounds, which have problems involving costs, toxicity, solubility, biodegradability and other problems. We have, therefore, initiated the use of novel methods of producing oxygenated diesel fuel via the F-T reaction as in Task I; we also hope to change the product distribution so that F-T products do not completely obey Schulz-Flory kinetics.

A continuous F-T unit is in operation with excellent analytical facilities. Product distribution from a preliminary F-T run with an alkalized iron catalyst is shown in Figure 1. A preliminary run with a cobalt catalyst gave almost entirely saturated paraffins.

Work has been started on the addition of certain small molecules to the F-T synthesis. It is known that certain small molecules containing double bonds (olefins) or $\mathrm{CH}_{2}$ units as in $\mathrm{CH}_{2} \mathrm{Cl}_{2}$ initiate $\mathrm{F}-\mathrm{T}$ reactions or build into the products. Initial experiments have been carried out by adding acetals, vinyl ethers, hexene and styrene epoxides or compounds containing a triple bond to iron-catalyzed F-T reactions with varying hydrogen to carbon ratios. The most interesting results have been obtained using the acetylene-type molecules; these are incorporated into the F-T products yielding oxygenated products, mostly alcohols and aldehydes. It seems that a hydroformylation reaction accompanies the iron-catalyzed F-T reaction although iron is a very poor hydroformylation catalyst; this is a completely unexpected finding which undoubtedly reflects the fact that carbon monoxide and acetylene both contain triple bonds which compete for 
the same active sites on F-T catalysts or change the mode of addition of synthesis gas in the F-T synthesis.

The product with alkali-promoted F-T catalysts contains large amounts of olefins. The product distribution obtained in an experiment using an iron catalyst promoted with potassium is shown in Figure 1. Reaction conditions were $1 \mathrm{~g}$ catalyst, $24 \mathrm{ml} / \mathrm{min} \mathrm{H}_{2}, 36 \mathrm{ml} / \mathrm{min} \mathrm{CO}, 260^{\circ} \mathrm{C}$ and 100 psi. The olefins that are produced with alkali promoted F-T catalysts can then be converted to primary alcohols by hydroformylation as an extension of the F-T reaction. The hydroformylation reaction involves the addition of synthesis gas to olefins.

$$
\mathrm{R}-\mathrm{CH}=\mathrm{CH}_{2}+\mathrm{CO}+2 \mathrm{H}_{2} \stackrel{\mathrm{Co} \text { orRh }}{\longrightarrow} \mathrm{R}-\mathrm{CH}_{2}-\mathrm{CH}_{2}-\mathrm{CH}_{2} \mathrm{OH}
$$

Work on this part of the project will be started as part of this year's research.

Figure 1.Product Distribution of FT Reaction on an Iron Catalyst

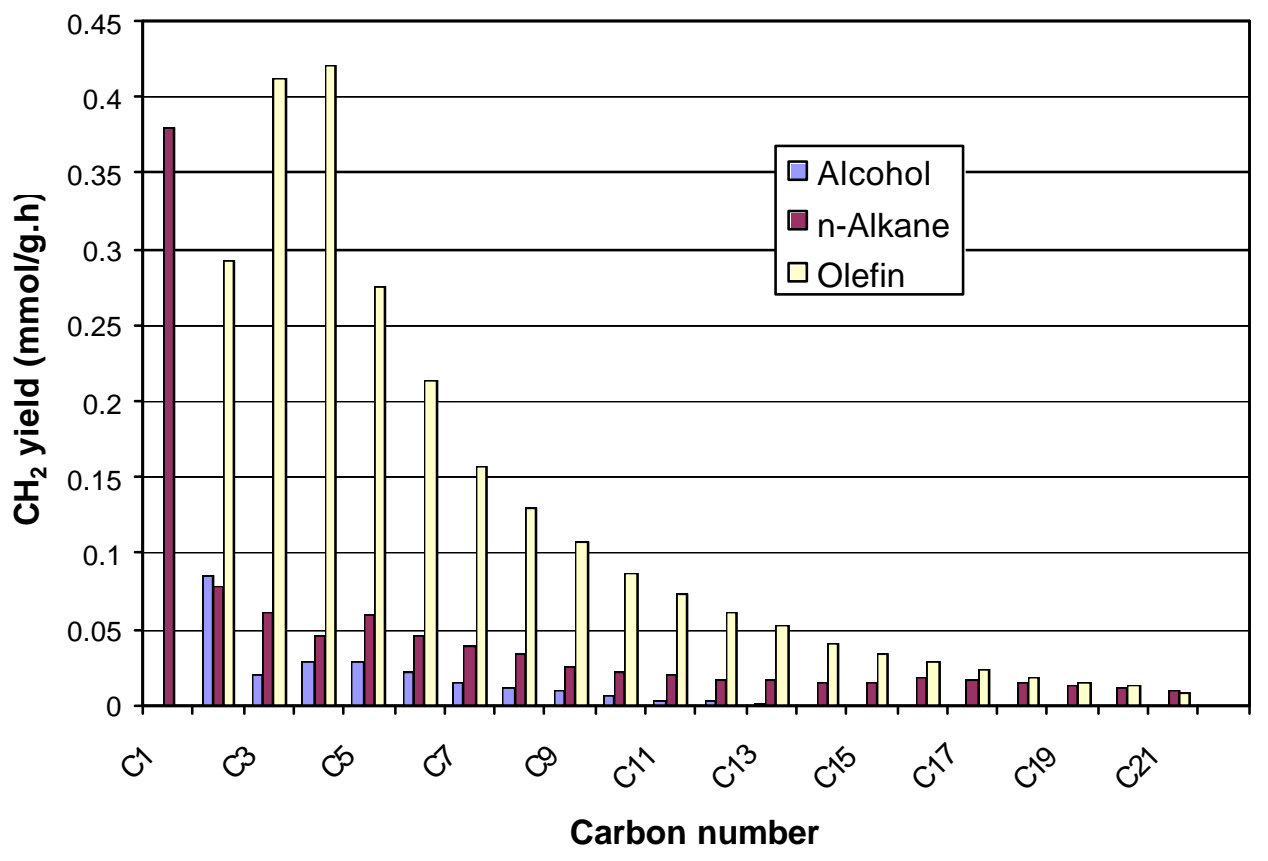




\section{Hydrogenation of F-T Products and Polyolefins to Environmentally Clean High Cetane Diesel Fuels, Jet Fuels and Lube -based Oils}

I. Wender, J.W. Tierney and G.D. Holder, University of Pittsburgh

Previous research in this laboratory investigated the activity of a platinumpromoted zirconia catalyst, $\mathrm{Pt} / \mathrm{ZrO}_{2} / \mathrm{SO}_{4}$, for the isomerization of n-heptane and $\mathrm{n}$ hexadecane. These catalytic systems, however, lost activity fairly rapidly due to the loss of sulfur from the catalyst. We then found that the substitution of tungsten trioxide $\left(\mathrm{WO}_{3}\right)$ for $\mathrm{SO}_{4}$ resulted in a more stable and selective catalyst for the hydroisomerization of n-hexadecane.

Laboratory work was then carried out successfully in a small continuous tricklebed reactor using the $\mathrm{Pt} / \mathrm{ZrO}_{2} / \mathrm{WO}_{3}$ catalyst. A $90-\mathrm{wt} \%$ iso- $\mathrm{C}_{16}$ selectivity and a $71 \mathrm{wt} \%$ iso- $\mathrm{C}_{16}$ yield were achieved at $79 \mathrm{wt} \%$ conversion of hexadecane. The objective in the last half-year has been to extend research to the conversion of paraffins longer than hexadecane, such as those produced in the F-T process, to a variety of clean transportation fuels. This was carried out using the stable and selective $\mathrm{Pt} / \mathrm{ZrO}{ }_{2} / \mathrm{WO}_{3}$ catalyst to hydroisomerize and hydrocrack pure compounds, namely n- $\mathrm{C}_{16}, \mathrm{n}-\mathrm{C}_{20}, \mathrm{n}^{-} \mathrm{C}_{24}$ and $\mathrm{n}-\mathrm{C}_{28}$, representative of alkane chains found in F-T products.

Catalytic activity tests were carried out in a $27 \mathrm{ml}$ micro autoclave system. In a typical reaction, $0.25 \mathrm{~g}$ of the catalyst was activated at $450^{\circ} \mathrm{C}$ for 40 minutes in air and then charged into a microreactor, which was predried overnight. After loading the catalyst, the reactant (typically $3 \mathrm{~g}$ ) was charged. The reactor was cooled to room temperature and hydrogen added. The reactor was shaken horizontally at $200 \mathrm{rpm}$. A computer was used to record the reaction pressure, temperature and time during the reaction. Cooling to room temperature terminated the reaction.

Since the catalyst and reactants were chosen, the remaining reaction variables are reaction time, reaction temperature, hydrogen pressure and hydrocarbon/catalyst ratios. Only the effects of reaction time and reaction temperature on product distributions were studied. The effect of hydrogen pressure was not studied because it is known that conversion decreases with increasing hydrogen pressure for platinum-promoted tungstate-modified zirconia catalysts. Both hydrogen and alkanes are competitively adsorbed on reduced $\mathrm{WO}_{3} / \mathrm{ZrO}_{2}$ clusters. When the hydrogen concentration increases, 
the surface density of carbocations decreases causing conversion to drop. Hydrogen pressure of 500 psig (cold) was used for all reactions. This value was chosen based on previous studies in this laboratory.

A typical GC chromatogram for the reaction of $\mathrm{n}-\mathrm{C}_{28}$ and the product fuel ranges are shown in Figure 1. Selectivity was calculated by dividing the total weight in the desired product range by the conversion of the reactant. Yield is defined as the ratio of the selected product range to the amount of reactant in the feed.

Figure 2 shows yield-product distribution graphs at three different conversions for octacosane $\left(\mathrm{C}_{28}\right)$ at $220^{\circ} \mathrm{C}$. It illustrates the yields to fuel ranges with increasing conversion. Figure $2-\mathrm{a}$ is at $79 \%$ conversion, Figure $2-\mathrm{b}$ at $92 \%$ conversion and Figure 2 -c at $99 \%$ conversion. The lube-base oil yield is highest at $79 \%$ conversion and consists of only branched isomers, mostly iso- $\mathrm{C}_{28}$. Yield of lube-base oil decreases gradually with increasing conversion as the yield of diesel fuel and gasoline increases. However, most interestingly, the major part of the product becomes diesel fuel at $99 \%$ conversion, only a $20 \%$ change in conversion. If the reaction is carried to $100 \%$ conversion, the major product becomes highly branched gasoline. Switching between these three fuels occurs at high conversion values. It appears possible to obtain the desired fuel range by adjusting the conversion at a selected temperature but maintaining relatively high conversion.

The fuel ranges contain more than $75 \%$ branched isomers at all conversions. A highly branched isomer ratio results in a high octane number for gasoline and a low pour point for diesel and lube-base oil. The isomerization percentage increases slightly for gasoline and diesel fuel with increasing conversion, but this effect is negligible compared to the temperature effect.

Product distribution changes with increasing temperature (Figure 3). Temperatures are $220^{\circ} \mathrm{C}, 240^{\circ} \mathrm{C}$ and $250^{\circ} \mathrm{C}$ in Figure 3-a, b and c. All data are for 20minute reactions with $n-\mathrm{C}_{28}$. At $220^{\circ} \mathrm{C}, 79 \%$ conversion is reached while $100 \%$ conversion was attained at both $240^{\circ} \mathrm{C}$ and $250^{\circ} \mathrm{C}$. The reaction at $240^{\circ} \mathrm{C}$ reached $100 \%$ conversion before 20 minutes and cracking increased. This effect can be seen in the product distribution for reaction at $250^{\circ} \mathrm{C} ; 80 \%$ of the product is in the gasoline range 
with none in the lube-base range. The lube-base and most of the diesel fuel have already been cracked into gasoline. Low temperatures favor isomerization to branched alkanes.

Overall, temperature has a more significant effect on product distribution than time. The ability to vary time and temperature independently allows flexibility in the product. Moderate temperatures give rise to middle range products while lower temperatures favor heavier but branched products.

For this catalyst, hydroisomerization takes place first and then multibranched isomers begin to crack. Both catalyst properties and reaction conditions have an effect on the hydroisomerization and hydrocracking balance and product distribution. By adjusting reaction time and temperature it is possible to obtain high conversion to diesel fuel, gasoline or lube-base oil. Selectivity to branched isomers is high at high conversions with this catalyst. Future studies will be made on a $50 \mathrm{ml}$, well-stirred autoclave with a number of catalyst supports. 


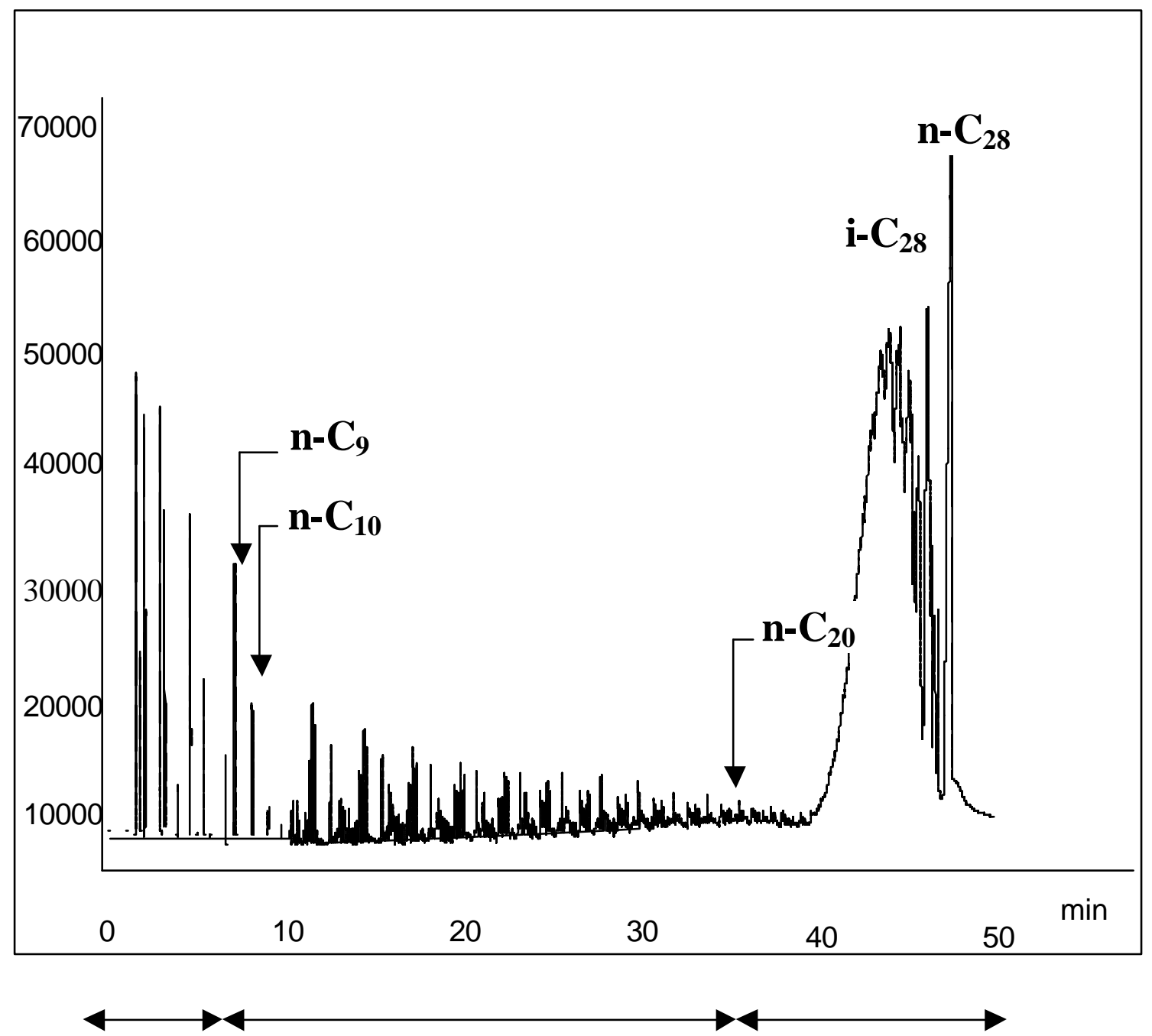

Gasoline Diesel Fuel Lube-Based Oil

Figure 1 Typical GC Chromatogram for Reacted Octacosane $\left(\mathrm{C}_{28}\right)$ at $220^{\circ} \mathrm{C}$ and 500 psig 
a-)

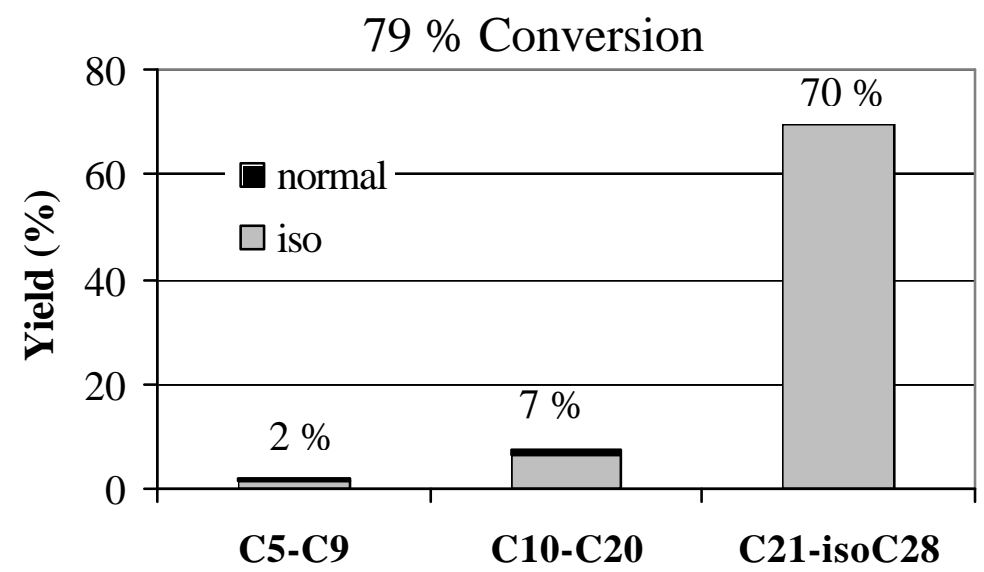

b- )

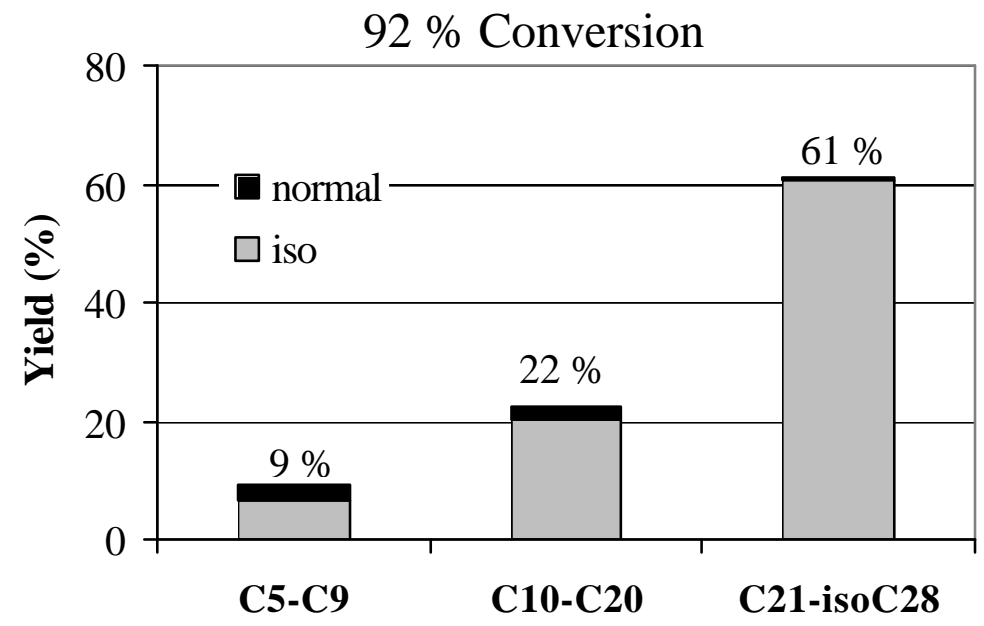

c-)

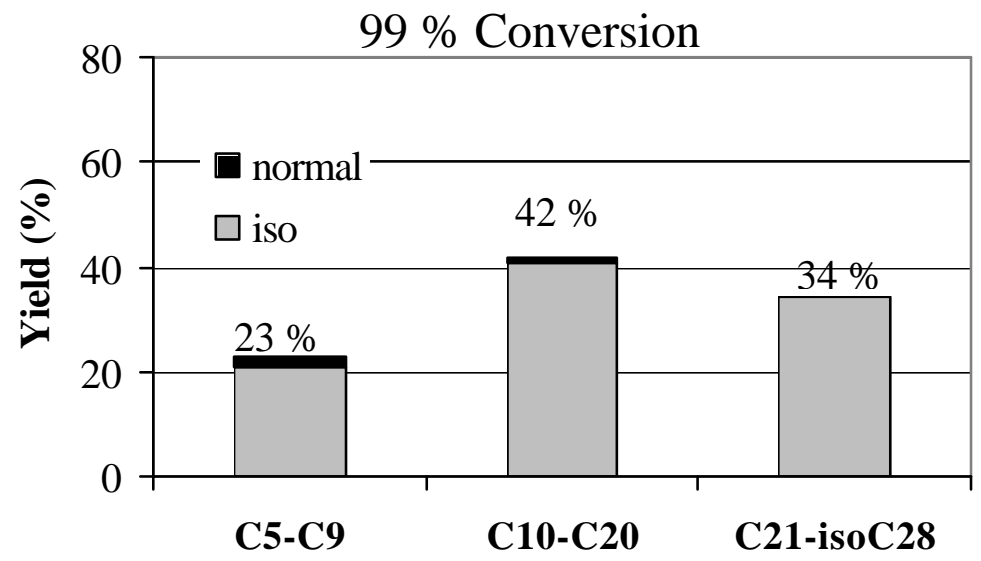

Figure 2 Effect of Conversion on Product Distribution for Reacted $\mathrm{C}_{28}$ at $220^{\circ} \mathrm{C}$ and 500psig 
a-)

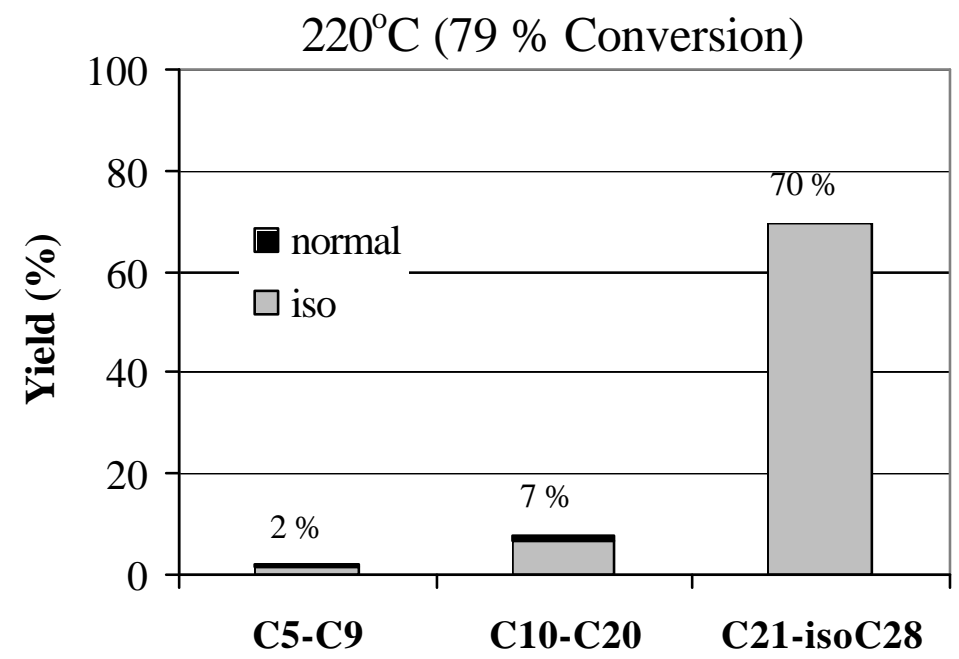

b-)

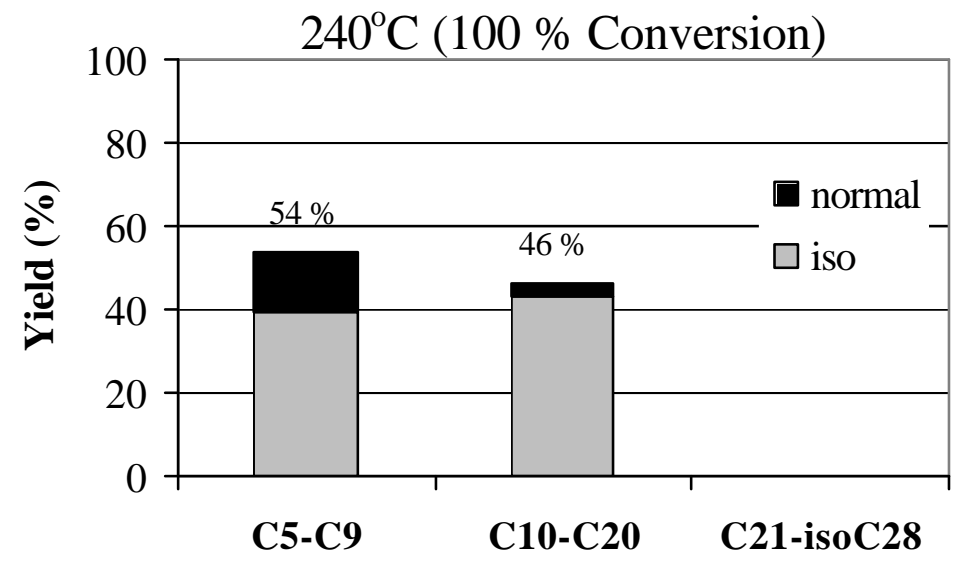

c-)

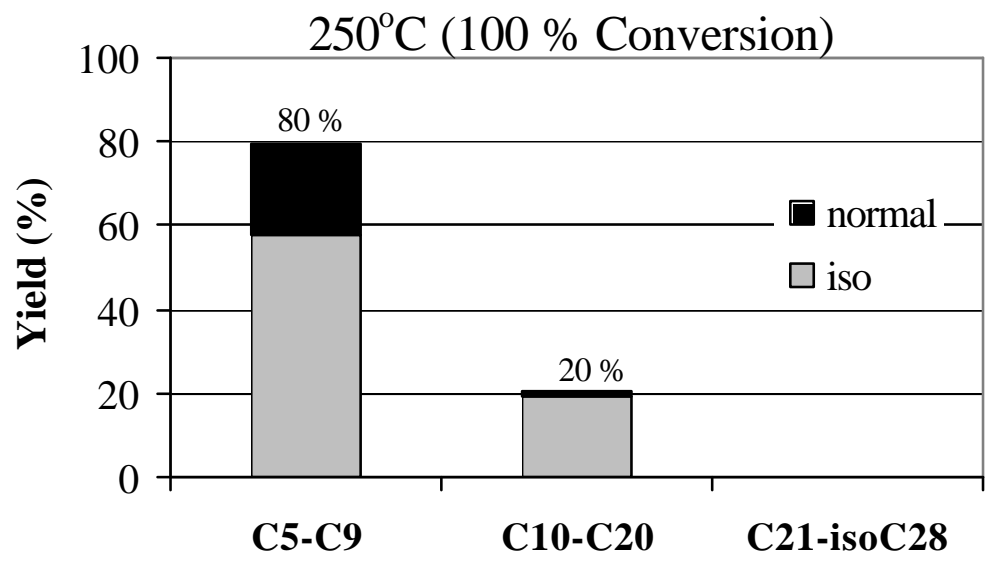

Figure 3 Effect of Temperature on Product Distribution of Reacted $\mathrm{C}_{28}$ at $220^{\circ} \mathrm{C}$ and 500 psig. 


\section{Dialkyl Carbonates from Alcohols and CO}

\section{E.M. Eyring, H. L. C. Meuzelaar, R. J. Pugmire and B. C. Dunn \\ University of Utah}

Diethylcarbonate may have future utility as an additive to diesel fuel. During the six months ending October 30, 2000, the University of Utah research group worked at identifying the species in $\mathrm{CuCl} / \mathrm{PdCl}_{2}$ heterogeneous catalysts that are responsible for speeding up diethylcarbonate (DEC) production:

$$
2 \mathrm{CH}_{3} \mathrm{CH}_{2} \mathrm{OH}+\mathrm{CO}+\frac{1}{2} \mathrm{O}_{2} \stackrel{\text { cat. }}{\longrightarrow} \mathrm{O}=\mathrm{C}\left(\mathrm{OCH}_{2} \mathrm{CH}_{3}\right)_{2}+\mathrm{H}_{2} \mathrm{O}
$$

The group had previously determined that acetate and nitrate catalysts do not perform as well as chloride salts do. It had also been found that an activated carbon support provides better yields of DEC than do alumina or silica supports. Other factors that had been identified as beneficial for DEC product selectability included reaction temperatures maintained below $170^{\circ} \mathrm{C}$ and pressures in the 200 to 300 psi range.

Since May, we have investigated the addition of metal hydroxides, especially $\mathrm{Ba}(\mathrm{OH})_{2}$, to the catalyst at the incipient wetness preparation stage.

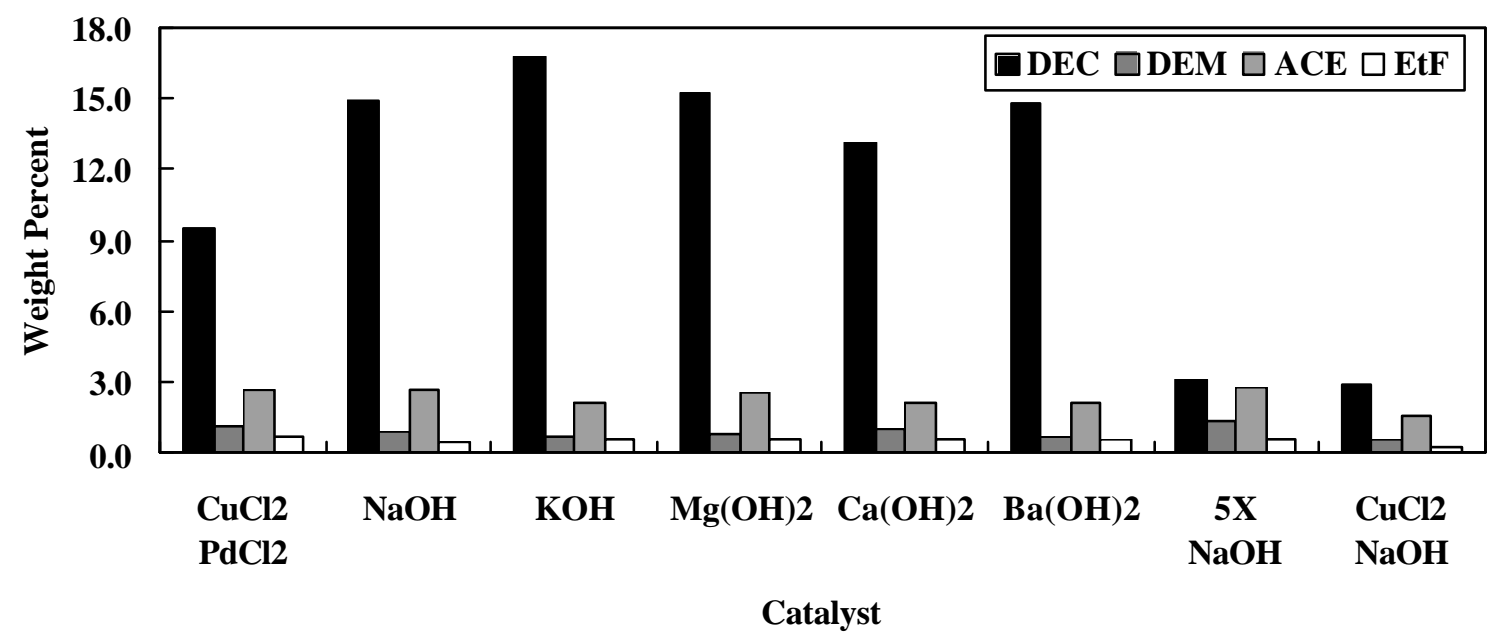

Figure 1. Final product distributions with indicated hydroxide metal salt added to $\mathrm{CuCl}_{2}+$ $\mathrm{PdCl}_{2}$ catalyst. All reactions performed under the following conditions: $0.5 \mathrm{~g}$ catalyst, $3.6 \mathrm{~g}$ $\mathrm{EtOH}, 40$ psi CO, 60 psi air, $100 \mathrm{psi}_{2}, 170^{\circ} \mathrm{C}, 4$ hrs. 
From a series of blank experiments, it has been determined that the formation of byproducts occurs in a chemical process that is independent of the formation of DEC. With no $\mathrm{CO}$ present in the reactor, substantial amounts of diethoxymethane (DEM), acetaldehyde (ACE), and ethyl formate (EtF) are produced with only a trace amount of DEC detected. This indicates that DEC is not an intermediate in the formation of any of the byproducts and that it may be possible to identify a catalyst that has a much higher degree of selectivity for DEC than has yet been observed.

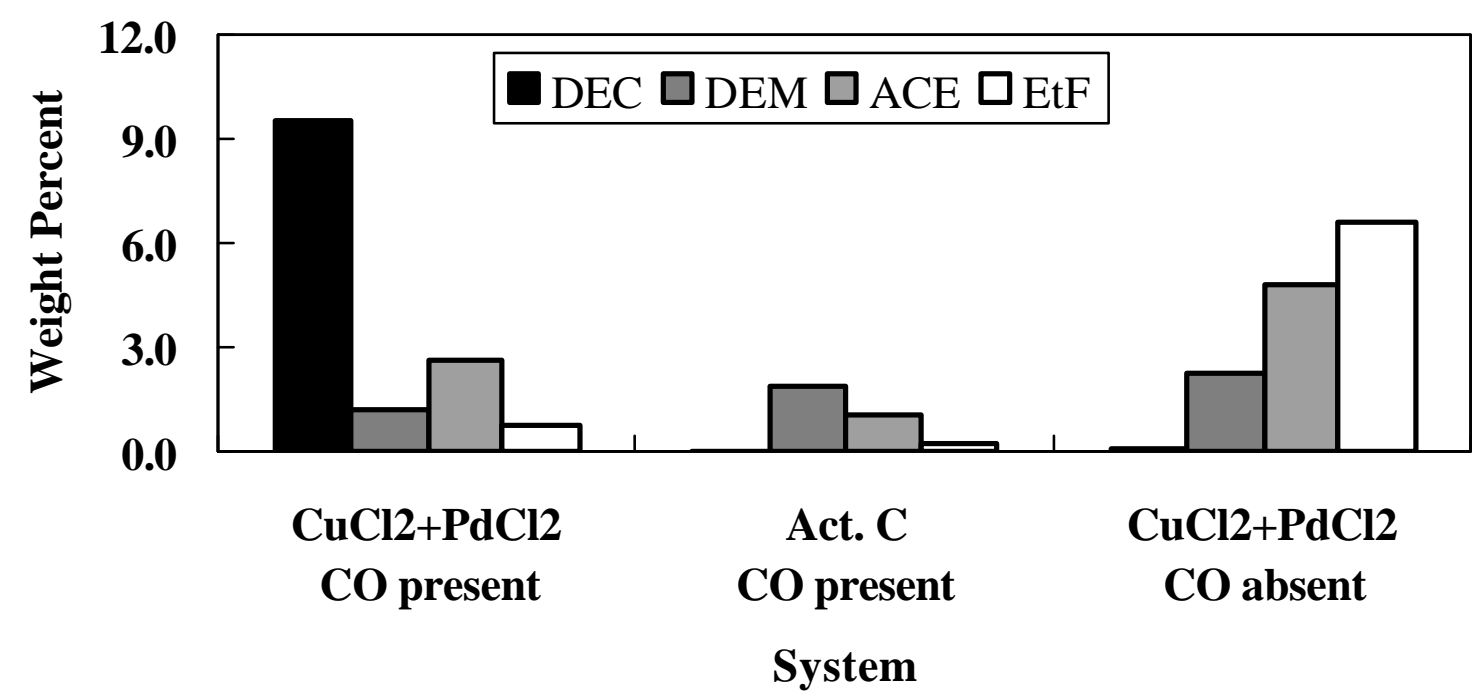

Figure 2. Final product distributions from two blank experiments. The activated carbon (Act. C) has no metal salt loading. The "CO absent" result has all reactants except for $\mathrm{CO}$. The first result is for comparison.

It has been found that the optimum mole ratio of hydroxide to $\mathrm{CuCh}$ in the catalyst is $0.50 . \mathrm{X}$ ray diffraction data obtained by the Seehra group (West Virginia) on the best catalyst prepared at the University of Utah showed that hydroxide addition to $\mathrm{CuCb}$ causes some of the copper in the catalyst to be converted into atacamite, an orthorhombic form of $\mathrm{Cu}_{2} \mathrm{Cl}(\mathrm{OH})_{3}$. The process occurs in the pores of the catalyst support thus limiting the diffusion of $\mathrm{OH}^{-}$. It is for this reason that atacamite forms rather than the more stable paratacamite, rhombohedral $\mathrm{Cu}_{2} \mathrm{Cl}(\mathrm{OH})_{3}$. Both minerals were synthesized by Dr. Brian Dunn (University of Utah) and tested as catalysts both neat and loaded on an activated carbon support. Neither mineral gave rise to DEC yields approaching those produced using in situ generated $\mathrm{CuCb} / \mathrm{PdCh} / \mathrm{Ba}(\mathrm{OH})_{2} /$ activated carbon catalysts. It appears that a catalyst that contains a mixture of $\mathrm{CuCl}(\mathrm{OH})_{3}$ and $\mathrm{CuCl}_{2}$ is the most effective for DEC production. Experiments are being carried out to establish the optimum mole ratio of these ingredients in catalysts prepared in situ by the incipient wetness method. 


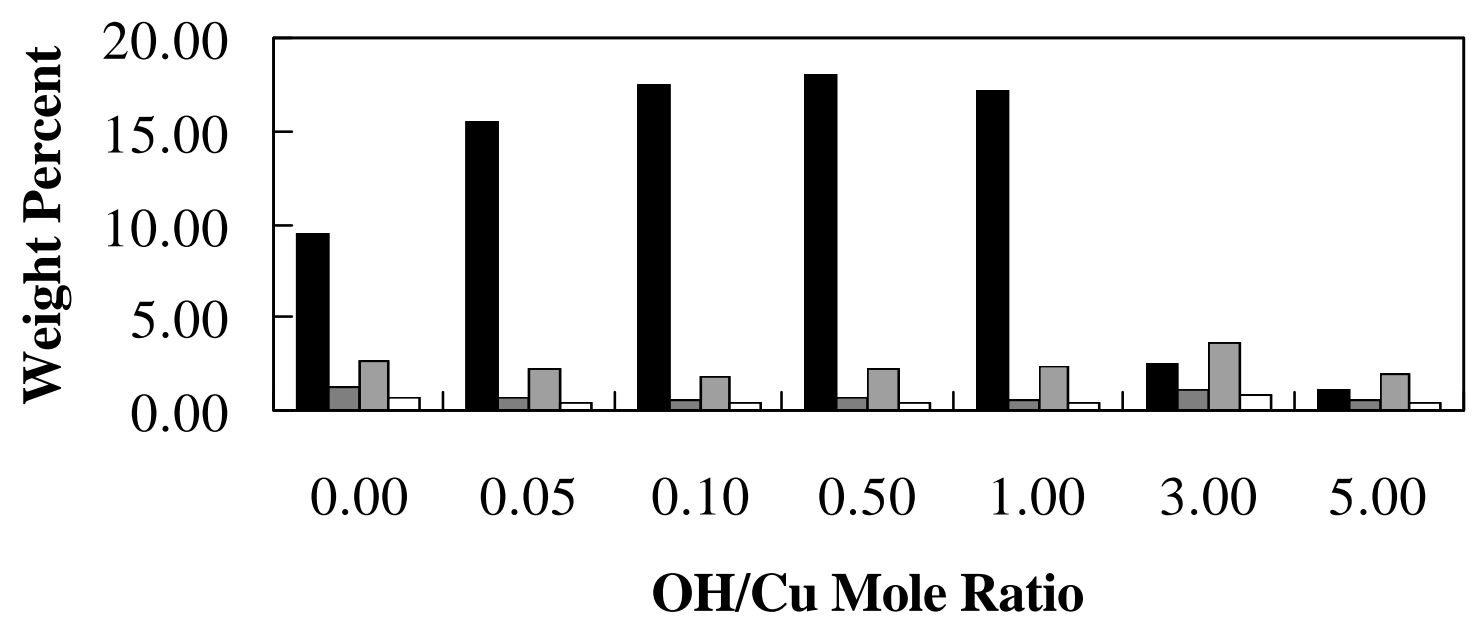

$\square \mathrm{DEC} \square \mathrm{DEM} \square \mathrm{ACE} \square \mathrm{EtF}$

Figure 3. Final product distributions with indicated mole ratio of hydroxide to copper. All reactions performed under the following conditions: $0.5 \mathrm{~g}$ catalyst, $3.6 \mathrm{~g} \mathrm{EtOH}, 40 \mathrm{psi} \mathrm{CO}, 60 \mathrm{psi}$ air, 100 psi $\mathrm{N}_{2}, 170^{\circ} \mathrm{C}, 4 \mathrm{hrs}$.

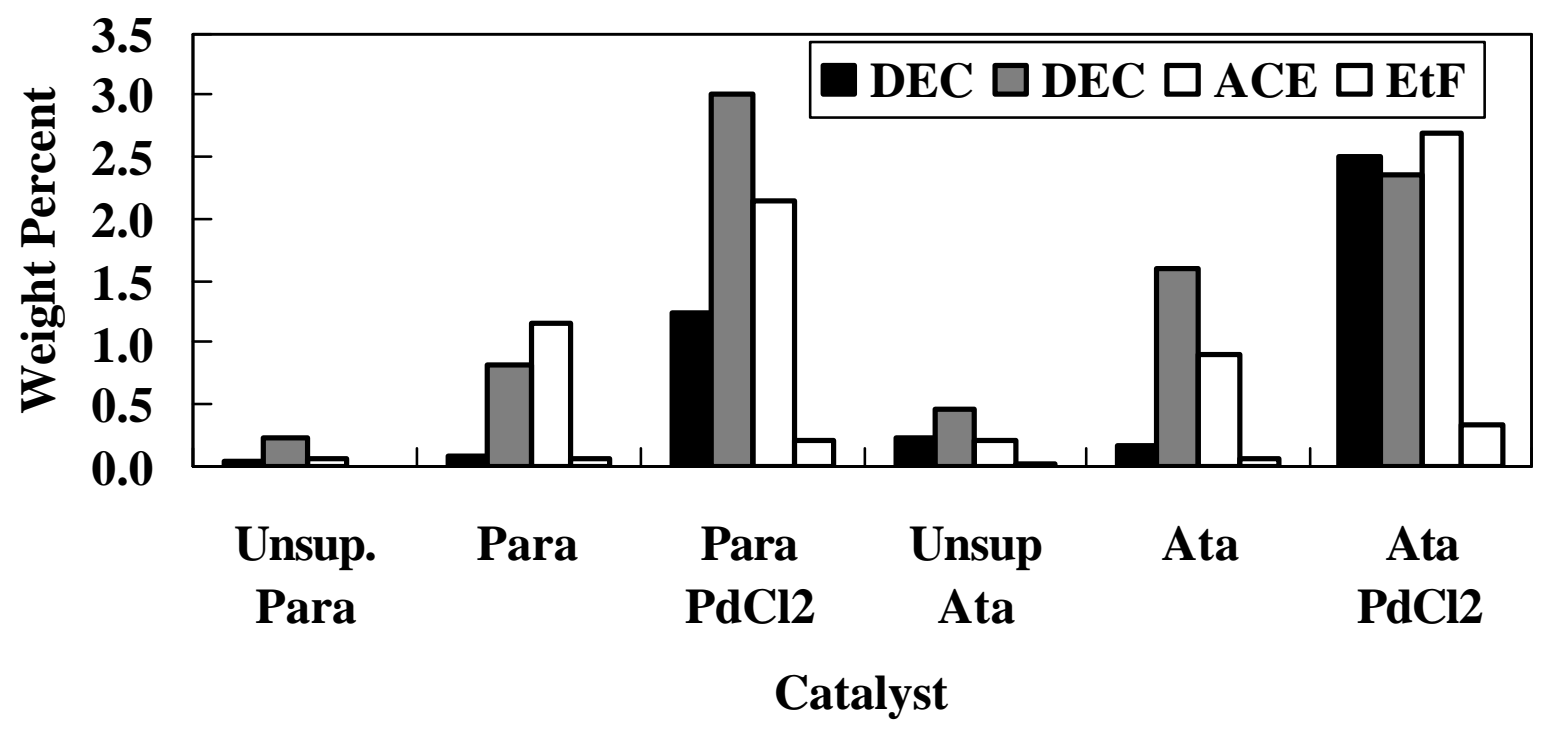

Figure 4. Final product distributions with $\mathrm{Cu}_{2} \mathrm{Cl}(\mathrm{OH})_{3}$ based catalysts. All reactions performed under the following conditions: $0.5 \mathrm{~g}$ catalyst, $3.6 \mathrm{~g} \mathrm{EtOH}, 40 \mathrm{psi} \mathrm{CO}, 60 \mathrm{psi}$ air, $100 \mathrm{psi} \mathrm{N}_{2}$, $170^{\circ} \mathrm{C}, 4 \mathrm{hrs}$. Para denotes paratacamite. Ata denotes atacamite. 
A preprint describing much of this work has been sent to the Fuel Chemistry Division of the American Chemical Society for possible presentation at the next national meeting of the Society in San Diego, CA in April 2001. The title of the preprint is "Production of Diethyl Carbonate from Ethanol and Carbon Monoxide Over a Heterogeneous Catalyst" by B. C. Dunn, C. Genneau, S. Hilton, E. M. Eyring, J. Dworzanski, H. L. C. Meuzelaar, J. Z. Hu and R. J. Pugmire.

All the personnel participating in this research effort are listed as co-authors of the above preprint. 


\title{
Synthesis of Higher Carbon Ethers from Methanol and Olefins
}

\author{
Shaobin Wang and James A. Guin \\ Department of Chemical Engineering, Auburn University
}

Acting on recommendations of the CFFLS Advisory Council and Industrial Advisory Board (IAB) Meeting in August, 2000, and subsequent meetings with CFFLS members, our project developing novel catalysts for the production of higher ethers as oxygenated fuel additives was redirected. It was felt that, based on recent developments with MTBE, the future use of ethers in transportation fuels may have limited potential. While our catalyst development efforts have now been redirected to a new focus, the time period for this particular 6-month report was largely spent on the catalyst development activities associated with the etherification efforts. Therefore, this progress report will consist of a summary of these final activities on our etherification project, prior to redirection. Detailed results are available in a series of papers that have been submitted for publication ${ }^{(1-5)}$.

In our etherification catalyst development work, numerous inorganic solid catalysts were prepared and tested for etherification of certain $\mathrm{C}_{6}$ olefins with methanol, and other alcohols and their catalytic activities were compared with the results obtained using some typical commercial ion-exchange resin catalysts such as Nafion and Amberlyst-15. Various parameters influencing the catalytic activity of the inorganic solids were also investigated.

The major reaction used to test the catalysts developed in our project was the etherification of 2,3-dimethyl-1-butene (23DM1B) or 2,3-dimethyl-2-butene (23DM2B) with methanol. In the process of etherification, as indicated in Figure 1, each olefin also undergoes isomerization on the catalyst. 23DM1B can be isomerized to 23DM2B, which further reacts with alcohols to produce ethers, although at a generally slower rate than 23DM1B. Even though both olefins are eventually converted to the same ether compound, for a nonequilibrium reaction, it is desirable to have high selectivity and yield to the ether, rather than to the olefin isomers.

In general, the inorganic solid catalysts that we prepared showed varying catalytic activities depending on the nature of the solids and preparation method. The commercial ion-exchange resin catalyst Amberlyst 15 was an effective but nonselective catalyst in etherification of $\mathrm{C}_{6}$ olefins with methanol and ethanol. Acid-treated silica and montmorillonite showed a comparable and sometimes even higher ether yield than the commercial resin catalysts. Nafion and silica 
supported Nafion were not as effective as the Amberlyst, being only slightly effective for etherification. Sulfuric acid modified silica systems exhibited good ether yields when compared to the commercial resin catalysts, and thus have potential as alternative catalysts for etherification of olefins.

Supported sulfated-zirconia (SZ) gave varying activity depending on the nature of support. Silica supported SZ exhibited a comparable ether yield to that of the commercial resin, with the catalytic activity influenced by the zirconium precursor, preparation technique, calcination temperature, the ratio of $\mathrm{SZ}$ on silica, promoters and reaction temperature.

MCM-41 supported sulfated zirconia and Nafion also were active catalysts for etherification of the $\mathrm{C}_{6}$ olefins with methanol. Their catalytic activity was dependent on the nature of support and preparation method. Catalysts prepared by impregnation techniques showed a better activity than those prepared by a sol-gel method. The loadings of sulfated zirconia and Nafion and reaction temperature also affected the catalytic activity. SZ/SiMCM41 and Nafion/Si-MCM41 both exhibited good ether yields measured against the commercial resin catalysts. Addition of transition metal oxide promoters also influenced the catalytic activity depending on the nature of promoter. $\mathrm{Ni}$ and $\mathrm{Pt}$ increased the catalytic activity but Fe showed no significant influence on olefin conversion. Mn reduced the catalytic activity. Generally, however, the promoters reduced the ether selectivity and yield as compared to the unpromoted versions. In conclusion, taken as a whole, our research has revealed several promising and potential catalysts for etherification of olefins with alcohols.

\section{References.}

1. Wang, Shaobin and Guin, J. A., "Silica-Supported Sulfated Zirconia: A New Effective Acid Solid for Etherification" Chem. Comm. ,Issue 24, (2000), 2499-2500.

2. Liu, Jing, Wang, Shaobin and Guin, J. A., (2000) "Etherification of Dimethylbutenes in Excess Methanol", submitted for Publication.

3. Wang, Shaobin and Guin, J. A., (2000), "Catalytic Activity of Silica Supported Sulfated Zirconia Catalysts for Liquid Phase Etherification of $\mathrm{C}_{6}$ Olefins with Alcohols" submitted for Publication.

4. Wang, Shaobin and Guin, J. A., (2000), "Si-MCM41 Supported Sulfated Zirconia and Nafion for Ether Production" submitted for Publication. 
5. Wang, Shaobin, Liu, Jing and Guin, J. A., (2000), "Etherification of C6 Olefins with Alcohols over Ion Exchange Resins and Superacid Solids" submitted for Publication.

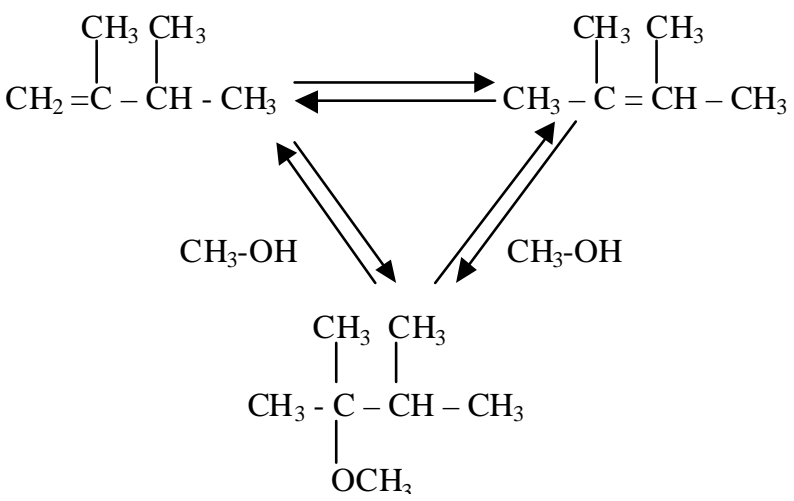

Figure 1. Reaction Network for Etherification of Dimethylbutenes. 


\title{
Higher Alcohol Synthesis from Methanol or Syngas
}

\author{
Abhay Pathania, Lawrence Norcio, Edwin L. Kugler and Dady B. Dadyburjor \\ Department of Chemical Engineering \\ West Virginia University \\ Morgantown, WV 26506-6102
}

\section{Introduction}

Alcohols are environmentally friendly fuel additives. Methanol, ethanol and both propanols are good gasoline-octane additives. Among higher alcohols, branched molecules provide greater octane increases than linear alcohols. Although methanol is a good octane enhancer, methanol addition must be limited because of its high vapor pressure. However, mixed alcohols in the $\mathrm{C}_{2}-\mathrm{C}_{6}$ range are well suited to be gasoline additives.

We are producing a single-phase liquid product of $\mathrm{C}_{1}-$ to- $\mathrm{C}_{6}$ alcohols with no liquidhydrocarbon phase. Methane, in small quantities, is the only gas-phase hydrocarbon product. This is a remarkable result. An iron catalyst cannot produce a single-phase alcohol product, but is limited to producing liquid-hydrocarbon-phase and liquid-water-phase products.

With iron catalysts, alcohol products are distributed between the two phases by solubility. Two liquid phases make easy separations impossible. This limitation does not exist with the catalysts described in this report.

\section{Summary of Results}

Work with prior students has shown that good alcohol synthesis performance can be obtained with alkali-promoted, molybdenum-on-carbon catalysts. Now we are working with new students and are striving to redevelop catalyst preparation skills, to validate prior work, and to move forward with higher-alcohol synthesis catalysts. Our initial emphasis with new students has been to obtain good material balance measurements. The computer-controlled reactor has 
been modified to maximize liquid product collection for carbon-balance measurements. Liquids are collected once a day while non-condensed gases are analyzed every two hours. The emphasis on good material balance data will validate prior work. This material balance data can be used also to check predictions made by non-ideal-gas thermodynamics, for we have a partial condensation with equilibrium between an associated liquid and a high-pressure gas.

Molybdenum on carbon catalysts promoted with nickel and potassium were prepared by impregnating $\mathrm{Mo}, \mathrm{Ni}$ and $\mathrm{K}$ successively and then calcining in nitrogen at $500^{\circ} \mathrm{C}$. The effect of hydrogen pretreatment time was tested by the reducing the catalyst at $400^{\circ} \mathrm{C}$ for 4 hours and for 12-15 hours. The longer pretreatment time increased alcohol production. Runs with 4 hours pretreatment produced 0-0.2 cc of mixed alcohols per 24 hours. Runs with 12-15 hours pretreatment increased alcohol production to approximately $1 \mathrm{cc}$ of liquid per 24 hours. Figure 1 shows a typical GC profile (FID detector) of mixed alcohols obtained after the longer hydrogen pretreatment. The liquid product collected is single-phase composed primarily of alcohols with a small quantity of water (measured with TCD detector). Higher alcohols $\left(\mathrm{C}_{4+}\right)$ are primarily branched.

The method of catalyst preparation was changed from impregnating $\mathrm{Mo}, \mathrm{Ni}$, and $\mathrm{K}$ successively and then calcining altogether in nitrogen at $500^{\circ} \mathrm{C}$ to calcining after each impregnation: $\mathrm{Mo}\left(500^{\circ} \mathrm{C}\right), \mathrm{Ni}\left(500^{\circ} \mathrm{C}\right)$, and $\mathrm{K}\left(300^{\circ} \mathrm{C}\right)$. Calcining the catalyst in nitrogen after each impregnation step increased alcohol production. Runs with catalyst prepared using successive calcination had increased alcohol yields of $2-2.5 \mathrm{cc}$ per 24 hours. The overall spacetime yield of mixed alcohols was $65 \mathrm{~g} / \mathrm{h} / \mathrm{kg}$ catalyst at $300^{\circ} \mathrm{C}$ and $650 \mathrm{psig}$.

Previous work has show that molybdenum-on-carbon catalysts can be fingerprinted using temperature programmed reduction measurements. Figure 2 shows an example of a TPR profile obtained from a Mo-Ni-K catalyst, which was calcined in nitrogen after each impregnation step. The TPR profile is somewhat different than those obtained previously. The significance of these differences will become apparent as we obtain more data from TPR and reaction studies. 


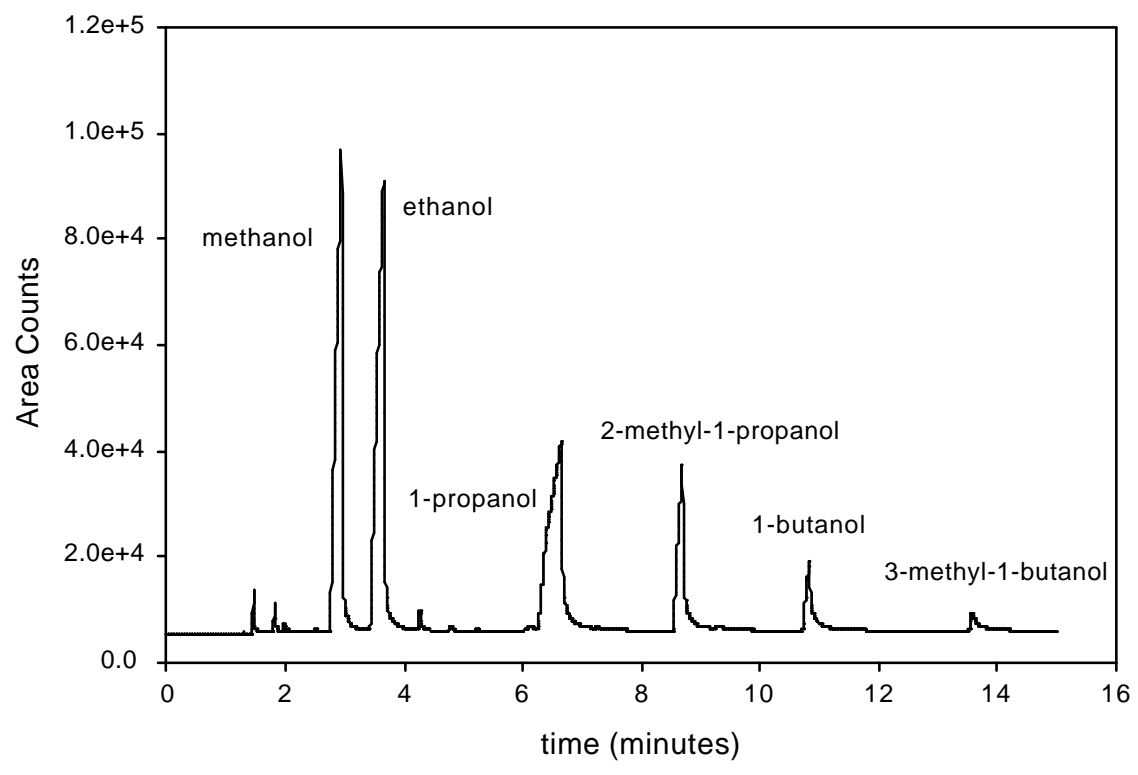

Figure 1- Typical gas chromatography profile of mixed alcohols.

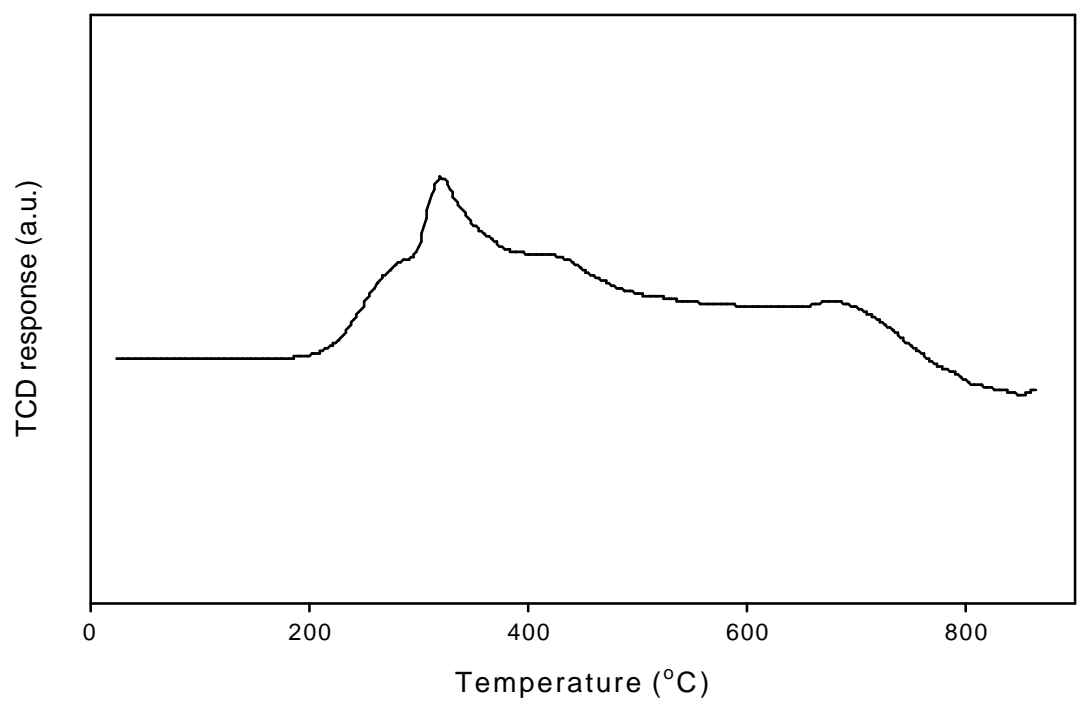

Figure 2- TPR spectra of calcined Mo, Ni, K/C.

The sequence denotes the order of impregnation.

The catalyst contain 18 wt. $\% \mathrm{Mo}, \mathrm{K} / \mathrm{Mo}=1.0$ (molar). 


\title{
Conversion of Synthesis Gas to Higher Ethers and Other Oxygenates
}

\author{
Christine W. Curtis, Christopher B. Roberts, Yoonkook Park \\ Chemical Engineering Department \\ Auburn University
}

\section{Synthesis of Higher Ethers from Syngas using a Single-Step Liquid Step Process}

The objective of this research is to develop improved transportation fuels by producing higher ethers and oxygenates for use as additives and blending agents in reformulated gasoline and ultra clean diesel fuels. The addition of oxygenates to gasoline and diesel fuels raises combustion temperatures, improves engine efficiencies, and causes the fuel to burn more cleanly, resulting in lower levels of carbon monoxide and unburned hydrocarbons in the exhaust stream. Ethers are the favored oxygen-containing additives for reformulated gasoline since they have high octane numbers and burn cleanly. Using higher ethers, as fuel additives would help achieve the goal of adding oxygenates with lower vapor pressures and lower water solubilities to the fuels while simultaneously increasing the energy density of the added oxygenate.

\section{Single-Step Liquid Phase Process}

The focus of this research is to develop a single-step, liquid phase process to produce higher ethers from synthesis gas. The conventional method of producing ethers is first to produce methanol from synthesis gas and then to convert the methanol to ether. For example, this process is typically used to produce dimethyl ether (DME) from methanol by either a gas or a liquid phase reaction (Peng et al., 1998; Sofianos and Scurrell, 1991; Espino and Pletzke, 1973). The conversion of syngas to methanol can be increased by removing, either chemically or physically, the alcohol as it is formed, because this removal lowers the thermodynamic constraints and promotes syngas conversion (Wender, 1996). A single-step, liquid phase DME synthesis reaction has been developed that converts DME directly from synthesis gas using a bifunctional catalyst that promotes methanol synthesis and methanol dehydration for forming 
DME (Lewnard et al., 1990). Performing this single-step reaction in a liquid phase environment offers the advantage of heat dissipation, thereby allowing a lower reaction temperature to be maintained. The liquid phase reaction results in less catalyst deactivation and longer catalyst lifetime (Brown et al., 1991).

The objective of this research is to develop a catalytic reaction system to produce higher ethers from synthesis gas and olefins using a single-step liquid phase reaction. In this system, as methanol is produced from syngas, the methanol would react with olefins to produce higher ethers. Diethers could also be synthesized from diolefins. One study (Kazi et al., 1995) has been found that has etherified methanol in a single step reaction for the synthesis of higher ethers. A dual catalyst bed was used with $\mathrm{Pd} / \mathrm{SiO}_{2}$ as the methanol synthesis catalyst and a zeolite as an etherification catalyst. The yield of ether from this reaction, which was operated at $175{ }^{\circ} \mathrm{C}$ and 7 atm, was very low. This result was most likely caused by the choice of catalyst. Not only is $\mathrm{Pd} / \mathrm{SiO}_{2}$ a methanol synthesis catalyst but it also serves as an effective hydrogenation catalyst for the added olefin, in this case isobutylene. The work that is currently underway will use a $\mathrm{CuO} / \mathrm{ZnO}$ on alumina methanol synthesis catalyst and dry Amberlyst 15 as the etherification catalyst at reaction temperatures ranging from 60 to $100{ }^{\circ} \mathrm{C}$.

\section{Experimental Results}

The reactions using straight chain olefins (1-hexene, 1-heptene, and 1-octene) with methanol performed at 100 and $150{ }^{\circ} \mathrm{C}$, showed no reactivity under both thermal and catalytic reactions. However, the experimental work involved reactions of branched $\mathrm{C}_{6}$ and $\mathrm{C}_{8}$ olefins, 2,3-dimethyl-1-butene (2,3DM1B), 2,3-dimethyl-2-butene (2,3DM2B), 2,4,4-trimethyl-1pentene (2,4,4TM1P), and 2,4,4-trimethyl-2-pentene (2,4,4TM2P), with methanol using 10 weight percent dry Amberlyst produced a significant amount of higher ethers, such as 2methoxy-2,3-dimethylbutane (2MO2,3DMB) and 2-methoxy-2,4,4-trimethylpentane (2MO2,4,4TMP) along with 2-hydroxy-2,3-dimethylbutane. The detectable amount of alcohol product produced in the course of etherification indicates that a small amount of water was present in the reaction mixture. 
Reaction time, reaction temperature, catalyst loading, and methanol/olefin ratio were selected to investigate how the operating conditions affect the product distribution as well as yield of ether products. From the results of reaction time and temperature effect on etherification, those reaction studied seems to be kinetically controlled reaction rather than thermodynamically controlled reaction because in almost all cases the ether compound produced converged approximately same mole percent in product after $6 \mathrm{hrs}$ reaction time.

Initially, 2:1 olefin to methanol ratio was selected because the methanol would most likely reacted as soon as it is formed. The amount of ether produced was less than $30 \%$. However, the amount of ether formed from the 2,3DM1B and 2,3DM2B at a 1:8 ratio was nearly doubled. Further, in the 2,4,4TM1P and 2,4,4TM2P reactions, the increased ratio had the effect of more than tripling the ether formation, indicating that the reaction had been starved for the methanol reactant. When the catalyst loading was increased to twice and three times the initial loading, the amount of ether produced was increased. Therefore, increased ether production was obtained by increasing the amount of methanol available for the reaction and by increasing the number of catalytic sites available to the olefins for the reaction.

The feasibility of producing higher ethers from $\mathrm{C}_{6}$ and $\mathrm{C}_{8}$ olefins has been demonstrated at temperatures below $80{ }^{\circ} \mathrm{C}$. Increasing the number of catalytic sites and the amount of methanol available for the reaction raised the ether production to reasonable level. The branched olefins have a greater reactivity than the straight chain olefins and are better candidates for producing higher ethers as diesel fuel additives.

\section{Theoretical Calculation}

The thermodynamics of the formation of higher ethers from synthesis gas was investigated by calculating the equilibrium composition of a system containing $\mathrm{CO}, \mathrm{H}_{2}$, all the possible isomer of the $\mathrm{C}_{1}$ through $\mathrm{C}_{4}$ alcohols, MTBE (methyl tert-butyl ether), $\mathrm{C}_{4}$ olefin (isobutylene), and two $\mathrm{C}_{7}$ ethers (isopropyl isobutyl ether and isopropyl butyl ether). These calculations were performed using the Gibbs free energy minimization module in the ASPEN 
PLUS process simulation package (Mawson et al., 1993). Parametric studies were performed to define the effects of temperature $\left(60 \sim 400{ }^{\circ} \mathrm{C}\right)$ at 100 atm of total pressure and fixed ratio of $\mathrm{H}_{2} / \mathrm{CO} /$ olefin $=2: 1: 1$ based upon the assumption that the final system is an ideal gas.

Scope of the Study: The reactions considered in this study were alcohol synthesis:

$$
\mathrm{n} \mathrm{CO}+2 \mathrm{n} \mathrm{H}_{2}=\mathrm{C}_{\mathrm{n}} \mathrm{H}_{2 \mathrm{n}+1} \mathrm{OH}+(\mathrm{n}-1) \mathrm{H}_{2} \mathrm{O} \quad(\mathrm{n}=1,2,3,4)
$$

and the formation of three different ethers of MTBE, and two $\mathrm{C}_{7}$ ethers were considered because the limitation of the available thermodynamic data in ASPEN PLUS. However, all of the possible isomers of propanol and butanol were considered, 1-propanol, 2-propanol, 1-butanol, 2 butanol, isobutyl alcohol, and t-butyl alcohol, as well as methanol and ethanol. Assuming that all of the species are gases with a standard state of 1 atm fugacity, the equilibrium expression has the form

$$
K_{j}=\prod_{i} f_{i}^{v_{i j}}=\prod_{i}\left(\phi_{i} p_{i}\right)^{v_{i j}}
$$

For an ideal gas, $\phi_{\mathrm{i}}=1.0$. The composition that follow were calculated using the Gibbs free energy minimization module entitled RGIBBS in the ASPEN PLUS computer software for chemical process flow sheet simulation. The temperature and total pressure of the system were specified as part of the input to the program, as were the number of moles of each component in the feed. The other required input to the program was the species present, i.e., all of the chemical compounds that are either reactants or products in any of he chemical reactions. For each compound, this data base contains the atomic formula, the values of critical temperature and pressure and accentric factor, and the thermochemical data, i.e., standard Gibbs free energy of formation, standard enthalpy of formation, and heat capacity as a function of temperature, that is required to minimize the total Gibbs free energy of the system.

For the reactants, $\mathrm{CO}, \mathrm{H}_{2}$, and isobutylene the results are expressed in terms of the percentage conversion, $\mathrm{X}_{\mathrm{i}}$, defined as 


$$
X_{i}=\frac{\text { in }- \text { out }}{\text { in }} \times 100
$$

Modeling Results. Table 1 shows the theoretical calculation result in etherification with the total pressure of $100 \mathrm{~atm}$ and fixed ratio of $\mathrm{H}_{2} / \mathrm{CO} /$ isobutylene $=2: 1: 1$. As temperature increased, not only the amount of ether products produced but also conversions of reactants are decreased. The ASPEN PLUS results indicate that the production of ethers from syngas appears feasible and easily controllable in terms of thermodynamics. However, if we consider the paraffins as a product, the product distribution changed dramatically, as can be seen in Table 2 . In other words, the synthesis of paraffins from syngas is a much more preferred reaction than the synthesis of ether. This result is in good agreement with the experimental results of MTBE single step formation reported by Kazi et al. (1995). They produced the measurable amount of MTBE during $\mathrm{CO}$ hydrogenation over dual beds of $\mathrm{Li}-\mathrm{Pd} / \mathrm{SiO}_{2}$ and a hydrogen zeolite $(\mathrm{HY}$ or $\mathrm{H}$ ZSM-5). However, the major products of that reaction were paraffins and olefins rather than oxygenates.

\section{Conclusions and Recommendations}

The higher ether compounds of 2-methoxy-2,3-dimethylbutane and 2-methoxy-2,4,4trimethylpentane from $\mathrm{C}_{6}$ olefins of 2,3-dimethyl-1-butene and 2,3-dimethyl-2-butene and $\mathrm{C}_{8}$ olefins of 2,4,4-trimethyl-1-pentene and 2,4,4-trimethyl-2-pentene with methanol were produced at temperature below $80{ }^{\circ} \mathrm{C}$ with Amberlyst 15 catalyst. The ASPEN PLUS process simulation package was used to determine the thermodynamic behavior of synthesis reactions of higher ethers from syngas. This thermodynamic analysis was performed before we initiated the construction of a single-step continuous reactor, which we proposed in last year. The simulation result shows that the hydrocarbon (paraffins and olefins) synthesis reactions are much more preferred at representative conditions of temperatures, pressure and feed composition, and with typical catalyst used in both alcohol and ether synthesis reaction. The possibility of multiphase product phases is excluded in this ASPEN PLUS simulation. 
Based upon this thermodynamic analysis, further consideration of this process will require careful consideration of two issues. The present thermodynamic calculation suggests that a new reactor design may be required if the reaction system approaches the limit of thermodynamic equilibrium. In addition to the development of a new reactor design, prudent selection of appropriate catalysts for synthesis of higher ethers should be undertaken. Currently, the investigation of single-step etherification from syngas should be considered cautiously unless more efficient reactors and/or catalysts are developed.

Table 1. Simulation Results 1. unit; [mol]

\begin{tabular}{lrrrrrr} 
Reaction temp. [K] & \multicolumn{1}{c}{333} & 353 & 373 & 473 & 573 & 673 \\
\hline \hline REACTANTS & & & & & & \\
$\mathrm{CO}$ & 0.0 & 0.0 & 0.1 & 1.5 & 13.6 & 62.8 \\
$\mathrm{H}_{2}$ & 0.0 & 0.1 & 0.1 & 2.9 & 24.2 & 125.5 \\
isobutylene & 0.4 & 1.3 & 3.6 & 42.8 & 61.6 & 85.3 \\
\hline PRODUCTS & 0.0 & 0.0 & 0.0 & 0.1 & 0.8 & 1.3 \\
methanol & 4.0 & 4.2 & 4.5 & 12.5 & 21.1 & 13.0 \\
ethanol & 22.7 & 23.0 & 23.9 & 37.4 & 31.8 & 11.4 \\
propyl alcohol & 22.7 & 23.0 & 23.9 & 37.4 & 31.8 & 11.4 \\
isopropyl alchol & 43.4 & 41.7 & 39.0 & 8.2 & 0.6 & 0.0 \\
\hline $\mathrm{C}_{7} \mathrm{H}_{16} \mathrm{O}^{2}$ & 7.2 & 8.0 & 8.5 & 2.9 & 0.3 & 0.0 \\
$\mathrm{C}_{7} \mathrm{H}_{16} \mathrm{O}^{b}$ & 0.0 & 0.0 & 0.0 & 0.0 & 0.0 & 0.0 \\
$\mathrm{MTBE}^{\text {conversion(\%) }}$ & & & & & & \\
\hline $\mathrm{CO}$ & 100.0 & 100.0 & 99.9 & 98.5 & 86.4 & 37.2 \\
$\mathrm{H}_{2}$ & 100.0 & 100.0 & 99.9 & 98.5 & 87.9 & 37.2 \\
$\mathrm{C}_{4} \mathrm{H}_{8}$ & 99.6 & 98.7 & 96.4 & 57.2 & 38.4 & 14.7 \\
\hline
\end{tabular}

a: isopropyl isobutyl ether, b: isopropyl butyl ether. 
Table 2. Simulation Results 2. Unit; [mol]

\begin{tabular}{|c|c|c|c|}
\hline Reaction temp. [K] & 333 & 353 & 373 \\
\hline \multicolumn{4}{|l|}{ REACTANTS } \\
\hline $\mathrm{CO}$ & 100.0 & 100.0 & 100.0 \\
\hline $\mathrm{H}_{2}$ & 0.0 & 0.0 & 0.0 \\
\hline isobutylene & 0.0 & 0.0 & 0.0 \\
\hline \multicolumn{4}{|l|}{ PRODUCTS } \\
\hline methanol & 0.0 & 0.0 & 0.0 \\
\hline ethanol & 0.0 & 0.0 & 0.0 \\
\hline propyl alcohol & 0.0 & 0.0 & 0.0 \\
\hline isopropyl alchol & 0.0 & 0.0 & 0.0 \\
\hline $\mathrm{C}_{7} \mathrm{H}_{16} \mathrm{O}^{a}$ & 0.0 & 0.0 & 0.0 \\
\hline $\mathrm{C}_{7} \mathrm{H}_{16} \mathrm{O}^{b}$ & 0.0 & 0.0 & 0.0 \\
\hline MTBE & 0.0 & 0.0 & 0.0 \\
\hline methane & 144.3 & 142.9 & 141.6 \\
\hline ethane & 4.5 & 5.3 & 6.1 \\
\hline propane & 7.4 & 8.2 & 9.1 \\
\hline butane & 11.3 & 11.9 & 12.4 \\
\hline pentane & 16.0 & 15.9 & 15.7 \\
\hline hexane & 16.6 & 15.8 & 15.1 \\
\hline \multicolumn{4}{|l|}{ conversion (\%) } \\
\hline $\mathrm{CO}$ & 0.0 & 0.0 & 0.0 \\
\hline $\mathrm{H}_{2}$ & 100.0 & 100.0 & 100.0 \\
\hline $\mathrm{C}_{4} \mathrm{H}_{8}$ & 100.0 & 100.0 & 100.0 \\
\hline
\end{tabular}

a: isopropyl isobutyl ether, b: isopropyl butyl ether.

\section{References}

Brown, D. M.; Bhatt B.L.; Hsiung, T.H.; Lewnard, J.J.; Waller, F.J.; "Novel Technology for the Synthesis of Dimethyl Ether from Syngas" Catalysis Today, 1991, 8, 279-304.

Espino, Ramon L.; Pletzke, Thomas S.; “Methanol Production”, US Patent US 3,888,896, assigned to ChemSystems, Inc., New York, NY, May 29, 1973.

Kazi, A.M.; Goodwin, J.G. Jr.; Marcelin, G.; Oukaci, R.; "Synthesis of MTBE during CO Hydrogenation: Reaction Sites Required” Ind. Eng Chem. Res., , 1995, 34, 718-721.

Lewnard, J.J.; Hsiung, T.H.; White, J.F.; Brown, D.M.; "Single-Step Synthesis of Dimethyl Ether in a Slurry Reactor" Chem. Eng. Sci., 1990, 45(8), 2735-2741.

Mawson, S.; McCutchen M. Shawn; Lim, Phooi K; Roberts, George W.; "Thermodynamics of Higher Alcohol Synthesis", Energy \& Fuels, 1993, 7, 257-267. 
Peng, Xiang-Dong; Parris, Gene E.; Toseland, Bernard A.; Battavio, Paula J.; "Use of aluminum phosphate as the dehydration catalyst in single step dimethyl ether synthesis", US Patent US

5,753,716 to Air Products and Chemicals, Allentown, PA, May 19, 1998.

Sofianos, A.C.; Scurrel, M.S.; "Conversion of Synthesis Gas to Dimehtyl Ether over Bifunctional Catalytic Systems" Ind. Eng Chem. Res., 1991, 30(11), 2371-2383.

Wender, Irving; "Reaction of Synthesis Gas", Fuel Processing Technology, 1996, 48(3), 216218. 


\title{
Supercritical Fluids as an Alternative Reaction Medium for Fischer-Tropsch Synthesis
}

\author{
Christopher B. Roberts, Christine W. Curtis, Xiwen Huang \\ Department of Chemical Engineering, Auburn University, Alabama, 36849
}

\section{Introduction}

Supercritical fluids have offered many advantages over traditional solvents for its low viscosity and high diffusivity of SCFs resulting in superior mass transfer characteristics; low surface tension enabling easy penetration into the pores of a solid matrix(catalyst) for extraction of nonvolatile materials in the pores; high compressibility near the critical point inducing large changes in density with very small changes in pressure and /or temperature enabling separation of the dissolved material easily and completely.

The unique properties of SCFs can be exploited in various ways for the design of heterogeneous catalytic reaction system. As a result, several classic industrial processes are conducted under SCF conditions, such as ethylene polymerization, ammonia synthesis and methanol synthesis. As an example of the potential of SCF reaction solvent, Li Fan et.al., investigated the effect of supercritical conditions on alkylation reactions on Y-type zeolites. Reactions under SCF conditions exhibited both higher catalyst activity, along with longer lifetimes compared to the reaction in the liquid or gas phase. SCF solvents offer many opportunities for heterogeneous catalysis in $\mathrm{C} 1$ chemistry.

The advantages of an SCF-phase F-T reaction are its gaslike diffusivity and liquid-like solubility, which means it could combine the desirable features of the gas- and liquid-phase synthesis routes. These advantages can be attributed to the SCFs offering high diffusivities and improved heat transfer (relative to a liquid) and high solubility (relative to a gas). The supercritical phase reaction also can (1)reduce production of undesirable products; produce less methane because of better distribution of heat in the reactor; (2)produce more long-chain olefins, probably because of the enhanced solubility of these higher hydrocarbons in the SCF; (3) migrate the coking and deactivation of catalyst because of the better heat removal ability; (4)bring the insitu extraction of heavy hydrocarbons from the catalyst surface and their transport out of the pores before they are transformed to consolidated coke, thereby extending catalyst lifetime; 
(5)enhance pore-transport of the reactants such as hydrogen to the catalyst surface thereby promoting the desired reaction pathways; (6)enhance desorption of the primary products preventing secondary reactions that adversely affect product selectivity.

\section{Objective}

The objective of our project is to explore the optimum operating condition to operate the FT synthesis reaction within the supercritical region itself; investigate the product selectivity alteration for FT synthesis when operated in a SCF medium vs. a liquid or gas medium; evaluate the feasibility of maintaining catalyst activity by continuous in situ extraction of products with a SCF medium; obtain an optimum method to increase the selectivity to desired products such as diesel and high-octane gasoline to improve the economics of FTS.

\section{Six-month Activity Report}

During the previous six months, we have focused our efforts on the function test and optimization of the fixed-bed continuous reactor system; Construction of a safety alarm detector system and computer controlled gas supply; Verification of On-line GC analysis system for evaluation of products up to C20 hydrocarbons and oxygenates and Performance of F-T synthesis reaction in supercritical hexane and pentane. Our efforts over the period involved the following items:

1. Individual system checks and function tests of the high-pressure fix-bed reactor system, which allows a wide range of temperatures (up to $400^{\circ} \mathrm{C}$ ), pressures (up to 200 bar). A computercontrolled gas flow system was designed, constructed, and tested including the development of appropriate process control software. This flow control system has been carefully calibrated and has been operated under pressure for extended periods of time. Appropriate safety-protection systems have been incorporated including a pressure relief system and high sensitivity gas sensors to warn of undesired concentrations of $\mathrm{CO}$ and $\mathrm{H}_{2}$ inside the laboratory.

2. An on-line GC analysis system was developed and tested including two GC's equipped with both TCD and FID detection of gas phase species and liquid phase hydrocarbons and oxygenates up to $\mathrm{C} 20$. 
3. Test reactions have been performed in supercritical n-hexane medium to verify reactor performance and establish operating parameters and limitations.

4. Steady-state SCF-based FT reactions in supercritical hexane and pentane are being performed over $15 \% \mathrm{Co}-0.5 \% \mathrm{Pt}-\mathrm{Al} 2 \mathrm{O} 3$ catalyst at a variety of pressure and temperature conditions to allow fundamental investigations of the effect of the SCF medium on the conversion of syngas, product selectivity and catalyst activity.

\section{Experimental}

A schematic diagram of the SCF-FT Reaction system is shown in the following Figure as assembled in our lab.

\subsection{Reactor Design}

The reactor itself measured $1.27 \mathrm{~cm}(0.5 \mathrm{in}) \times 25.4 \mathrm{~cm}(10 \mathrm{in})$ with an effective volume of $32 \mathrm{~cm}^{3}$. To fix the catalyst in place, a $15 \mathrm{~mm}$ (diameter), 2-3mm(thickness) and 4-15micron (porosity) fused quartz disc is put inside the reactor. In order to position the disc in the middle of the reactor, the inner diameter of the reactor above the disc was machined exactly to match the disc diameter, which a little larger than the section below the disc. Quartz disc was employed to avoid the use of any Fe-containing metal near the reaction zone. A schematic of the reactor and catalyst loading scheme is shown as follows: 
Fischer-Tropsch Reaction and Analysis System Schematic

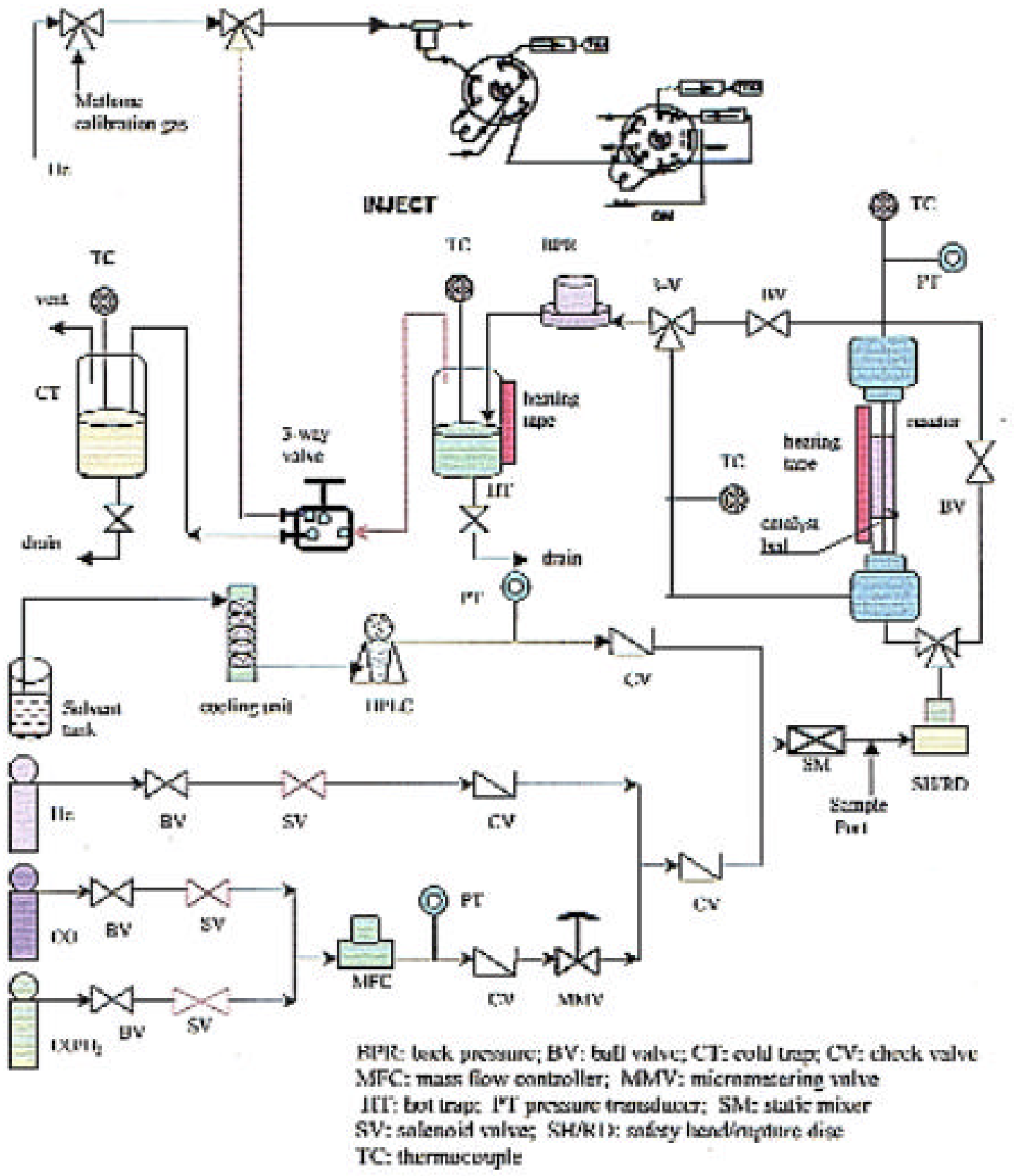




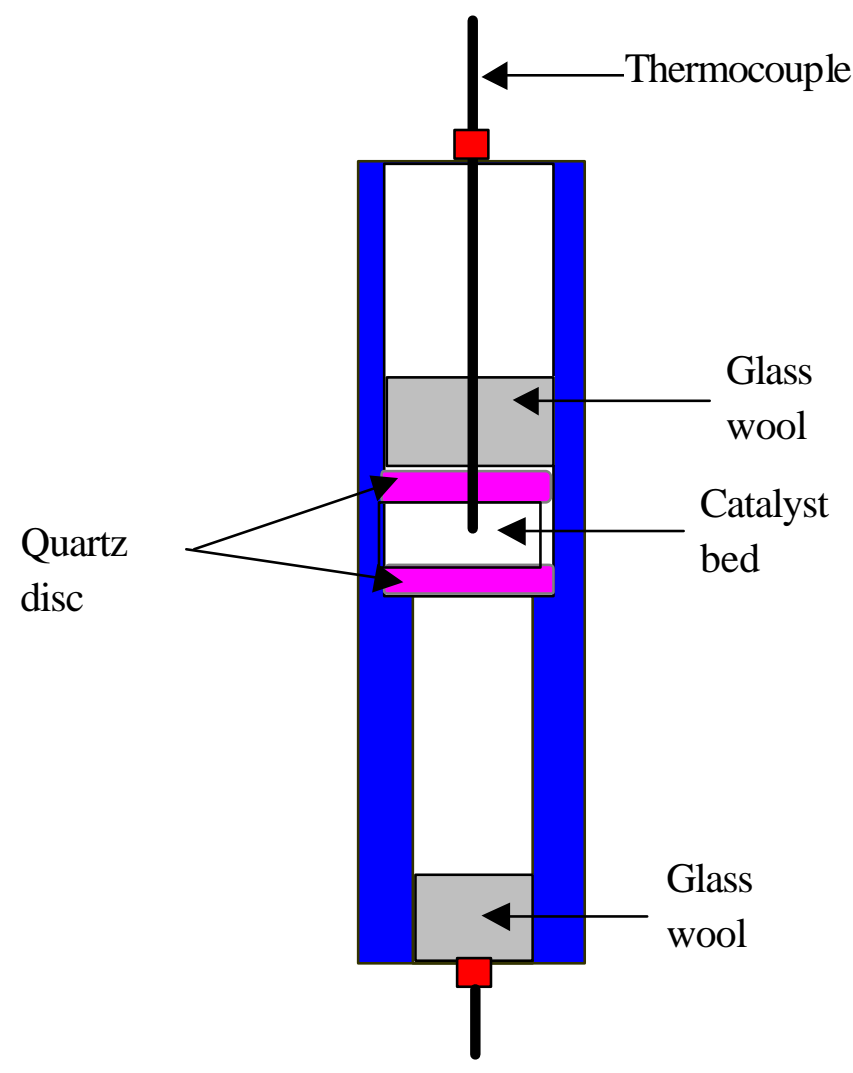

Catalyst loading diagram

\subsection{Catalyst Pretreatment}

The catalyst is so highly hygroscopic that it needed to be heated for an extended period of time $(>24 \mathrm{~h})$ at $150^{\circ} \mathrm{C}$ to remove absorbed water. $\mathrm{CO}$ is used as the pretreatment gas, after the reactor was in place, helium flow over the catalyst is initiated. The pressure in the reactor is set to $100 \mathrm{psi}$ while the flow rate is not controlled. Once the temperature of catalyst bed reaches $150^{\circ} \mathrm{C}$, the flow of $\mathrm{CO}$ begins at $50 \mathrm{sccm}$. Simultaneous to the initiation of the $\mathrm{CO}$ flow, the temperature of the catalyst is increased to $280^{\circ} \mathrm{C}$. When the pressure in the gas supply line exceeds $50 \mathrm{psi}$, the flow of helium is halted. When the temperature of the reactor outlet line reached $180 \mathrm{C}$, the line is maintained at that temperature, while the inlet and the reactor temperatures are increased to $280 \mathrm{C}$, which are held for $18 \mathrm{hrs}$ at that temperature. Once the hold 
time expires, the flow of $\mathrm{CO}$ is halted and the reactor is purged with high-purity helium at roughly $400 \mathrm{sccm}$. All the temperature levels are reduced to $240^{\circ} \mathrm{C}$ once the helium flow began, the catalyst bed in the reactor is kept at $240^{\circ} \mathrm{C}$ and 100psi under helium until the reaction begin.

\subsection{Reaction Procedure}

Once the HPLC pump flow rate is checked to guarantee a steady-state flow rate of $1.0 \mathrm{ml} / \mathrm{min}$, hexane flow is directed to the reaction system. The hexane passes through a static mixer, safety head, and with hexane flowing, the temperature and pressure of the reaction zone is raised to 240C and the particular pressure for the experiment. The hot trap is heated to 180C in order to vaporize as much as the product stream as possible for analysis. Lastly, the transfer line to the $\mathrm{GC}$ is heated to $220 \mathrm{C}$ to absolutely insure the stream directed to the GC would experience no condensation.

When all temperature and pressure are stabilized at reaction conditions, the flow of syngas is initiated. The mass flow controller is set to the appropriate value and control commenced. All the reactions are continued until a steady-state with respect to conversion and selectivity are attained. When the reaction is halted, the syngas flow is stopped while maintaining the hexane flow. Once the FT products are no longer detected in the effluent, the pressure is reduced to 100psi and the flow of hexane is stopped. Once the reaction pressure decreased to $200 \mathrm{psi}$, helium flow is started and the temperature of catalyst bed is allowed to drop to room temperature with helium flowing over it.

\subsection{Analysis Method}

Two GCs are used for the analysis system, which include Varian 3300 GC with capillary column(DB-5) and FID for the analysis of C5-C20 hydrocarbons and oxygenates; Varian CP3800 with capillary column(GS-GASPRO )TCD for the analysis of permanent gases and $\mathrm{G}_{5} \mathrm{C}_{5}$ hydrocarbons and oxygenates.

The typical GC analysis chromatogram of product includes C6- C12 alcohols, C9- C16 paraffins, and C9- C16 olefins

\section{Future Plans}


1) Demonstrate the advantages of performing SCF-based F-T synthesis reactions to selectively produce fuel range products by conducting continuous F-T synthesis in SCF hydrocarbons and $\mathrm{CO}_{2}$ in the presence of a variety of catalysts. 2) Perform kinetic analysis of reaction pathways under SCF F-T conditions and perform fundamental investigations of the SCF solvent's effect on reaction mechanisms, catalyst activity, reaction rates, heat and mass transfer, and selectivities. 3) Based on these fundamental investigations, the SCF reactor design and operation will be optimized to enhance syngas conversion and improve control over the desired product distributions. 


\section{Reforming of Natural Gas with Carbon Dioxide \\ Mahesh V. Iyer, Lawrence Norcio, Edwin L. Kugler and Dady B. Dadyburjor \\ Department of Chemical Engineering \\ West Virginia University \\ Morgantown, WV 26506-6102}

\section{Introduction}

Natural gas is expected to outlast oil reserves by a significant margin. In recent years, the reforming of methane with carbon dioxide for the production of synthesis gas has received considerable attention for the following reasons: (1) It produces synthesis gas with higher purity and lower $\mathrm{H}_{2} / \mathrm{CO}$ ratio than either partial oxidation or steam reforming; (2) Two greenhouse are utilized; (3) $\mathrm{CO}_{2}$ is frequently a significant component of natural gas and is produced in many industrial processes; (4) It can be employed in places where clean water is not readily available.

We have found that dry reforming with a cobalt-tungsten carbide catalyst gives both high conversion and high $\mathrm{H}_{2}-\mathrm{CO}$ ratios. The catalyst is stable over extended periods of time. This remarkable combination of high conversion and high selectivity is the subject of this report.

\section{Summary of Results}

A computer-controlled testing unit with on-line product analysis was used for catalyst evaluation. The cobalt-tungsten carbide catalyst was tested for activity at different temperatures, particle sizes, pretreatment conditions, feed ratios and weight hourly space velocity (WHSV) of the reactants. The catalyst was found to be very stable even after 140 hours of reaction run at $1123 \mathrm{~K}$ (Fig. 1). Under these conditions, the catalyst shows an increase in conversion during the first 20 hours of the run. X-ray data for end-of-run catalyst show that a phase change occurred to produce a tungsten carbide in cobalt catalyst. For a feed ratio of 1:1 and a particle size of less than 38 microns, the $\mathrm{CH}_{4}$ and $\mathrm{CO}_{2}$ conversions obtained were 62 and $72 \%$, respectively, and the $\mathrm{H}_{2} / \mathrm{CO}$ ratio was close to 1 , even after 140 hours. In the absence of high-temperature catalyst 
activation, the conversions were 44 and $62 \%$, respectively, and the $\mathrm{H}_{2} / \mathrm{CO}$ ratio was much smaller.

Dry reforming at high temperatures involves at least three independent reactions.
$\mathrm{CH}_{4}+\mathrm{CO}_{2} \longrightarrow 2 \mathrm{CO}+2 \mathrm{H}_{2}$
(Methane Reforming)
$\mathrm{CO}_{2}+\mathrm{H}_{2} \longrightarrow \mathrm{H}_{2} \mathrm{O}+\mathrm{CO}$
(Reverse Water-Gas Shift, RWGS)
$2 \mathrm{CO}$

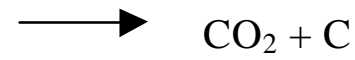
(Carbon Deposition)

Rates for each reaction are determined by using extent-of-reaction calculations. Figure 2 shows the results of fitting a power-law model to the methane reforming reaction rate under a wide range of temperatures and feeds. Data points are scattered about the solid line that shows agreement between experimental and predicted values, showing that the observed and predicted rates agree reasonably well.

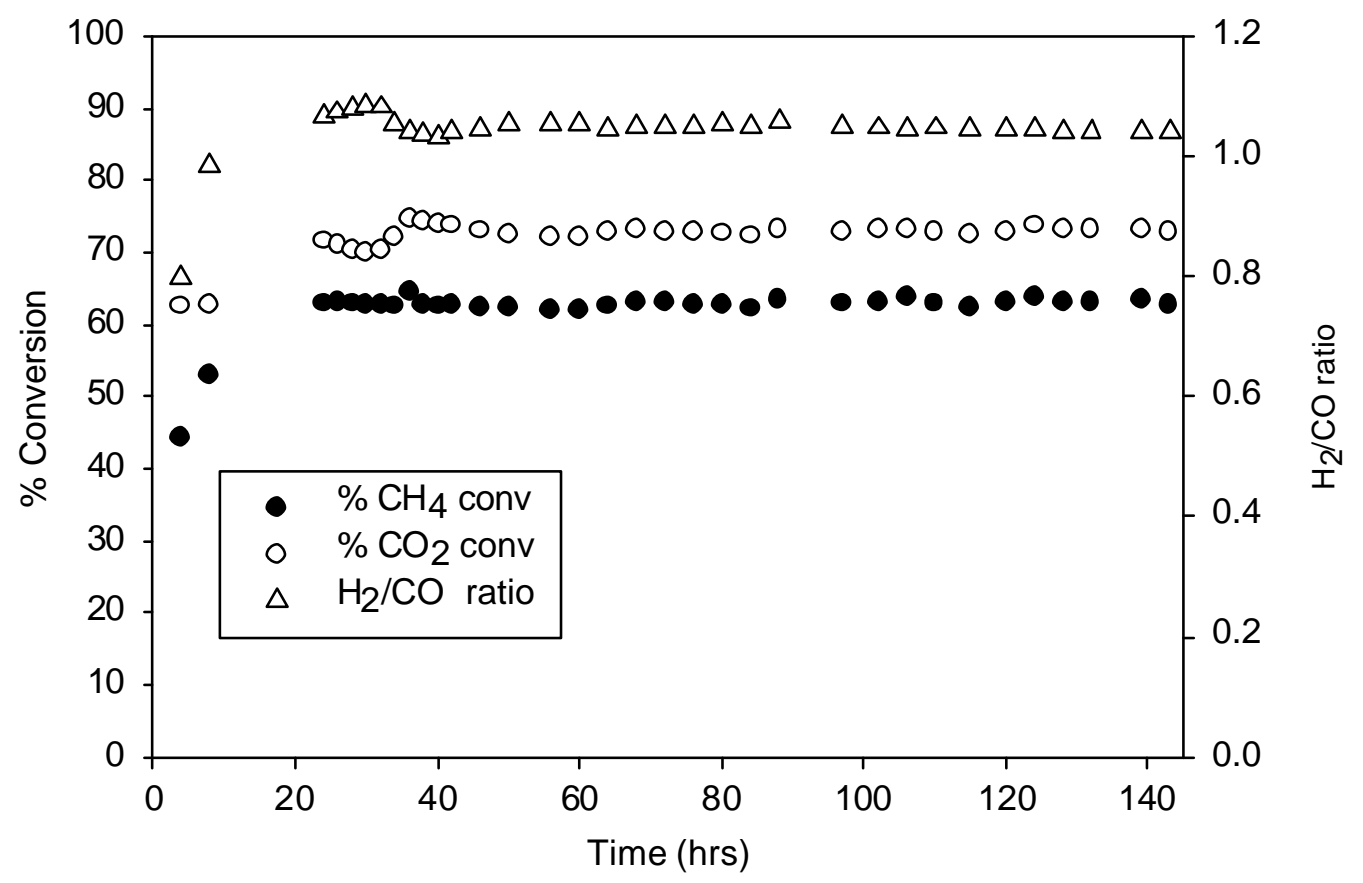

Figure

\section{1 - Lifetime Study of the $\mathrm{Co}_{6} \mathrm{~W}_{6} \mathrm{C}$ Catalyst}




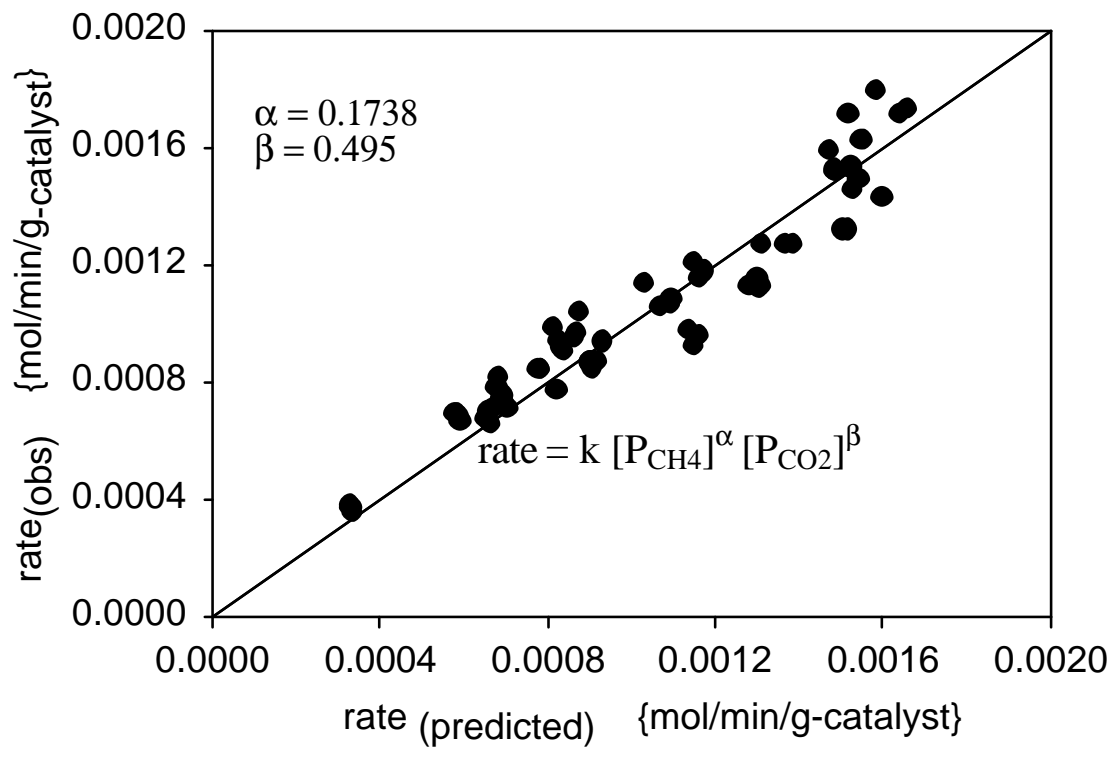

Figure 2 - Comparison of Observed and Predicted Methane Reforming Rates 


\section{Hydrogen Production by Non-Oxidative Catalytic Decomposition of Methane}

Devadas Panjala, Naresh Shah, and Gerald Huffman, University of Kentucky

Production of pure hydrogen from hydrocarbons, particularly methane, the major component of natural gas, has great practical importance. Traditionally, dry (with $\mathrm{CO}_{2}$ ) reforming, wet (with $\mathrm{H}_{2} \mathrm{O}$ ) reforming and partial oxidation of methane are employed to produce synthesis gas. Converting $\mathrm{CO}$ in synthesis gas using the water-gas shift reaction then produces a relatively pure hydrogen stream. However, this hydrogen still contains enough CO to poison the catalysts used in PEM electrochemical fuel cells. A reverse methanation reaction has to be carried out to reduce the $\mathrm{CO}$ concentration to sub-ppm levels. Non-oxidative catalytic decomposition of hydrocarbons to produce pure hydrogen is an alternative route to avoid the presence of $\mathrm{CO}$. In the current investigation, nanoscale ferrihydrite and binary ferrihydrites supported on alumina were subjected to various pre-treatments, and were found to be effective catalysts for methane decomposition.

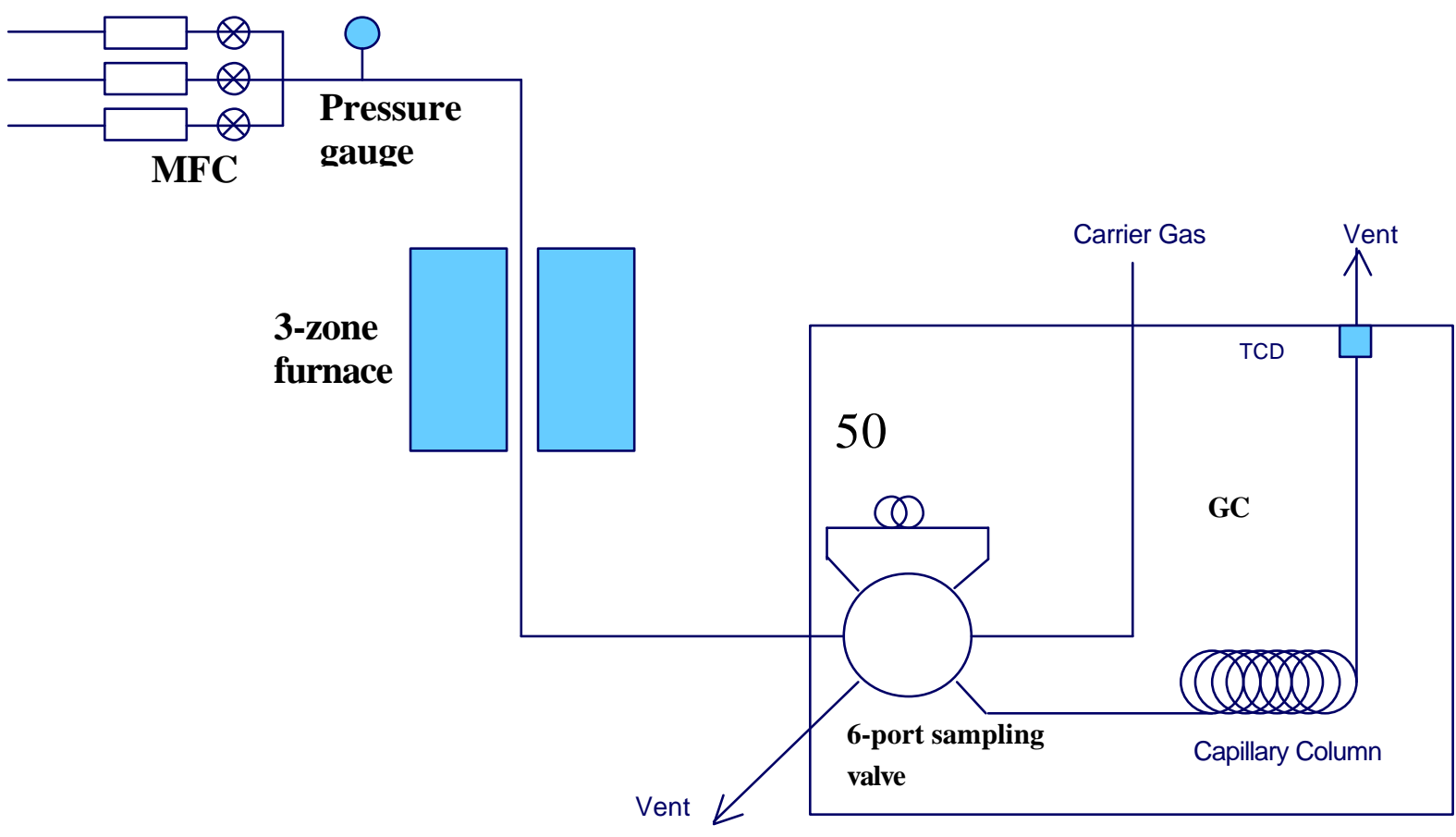

Figure 1: Schematic of experimental set-up for studying catalyst performance for decomposition of methane. 
Figure 1 is a schematic of the experimental set-up used for studying catalyst performance. A calibrated volume of the undiluted reactant (methane) stream is passed through a catalyst bed kept at a fixed temperature. The entire product stream passes through a sampling valve loop. Periodically, by switching the valve position, the sample contained in the sampling loop is injected to the GC column and the gaseous components are separated and quantified using a TCD.

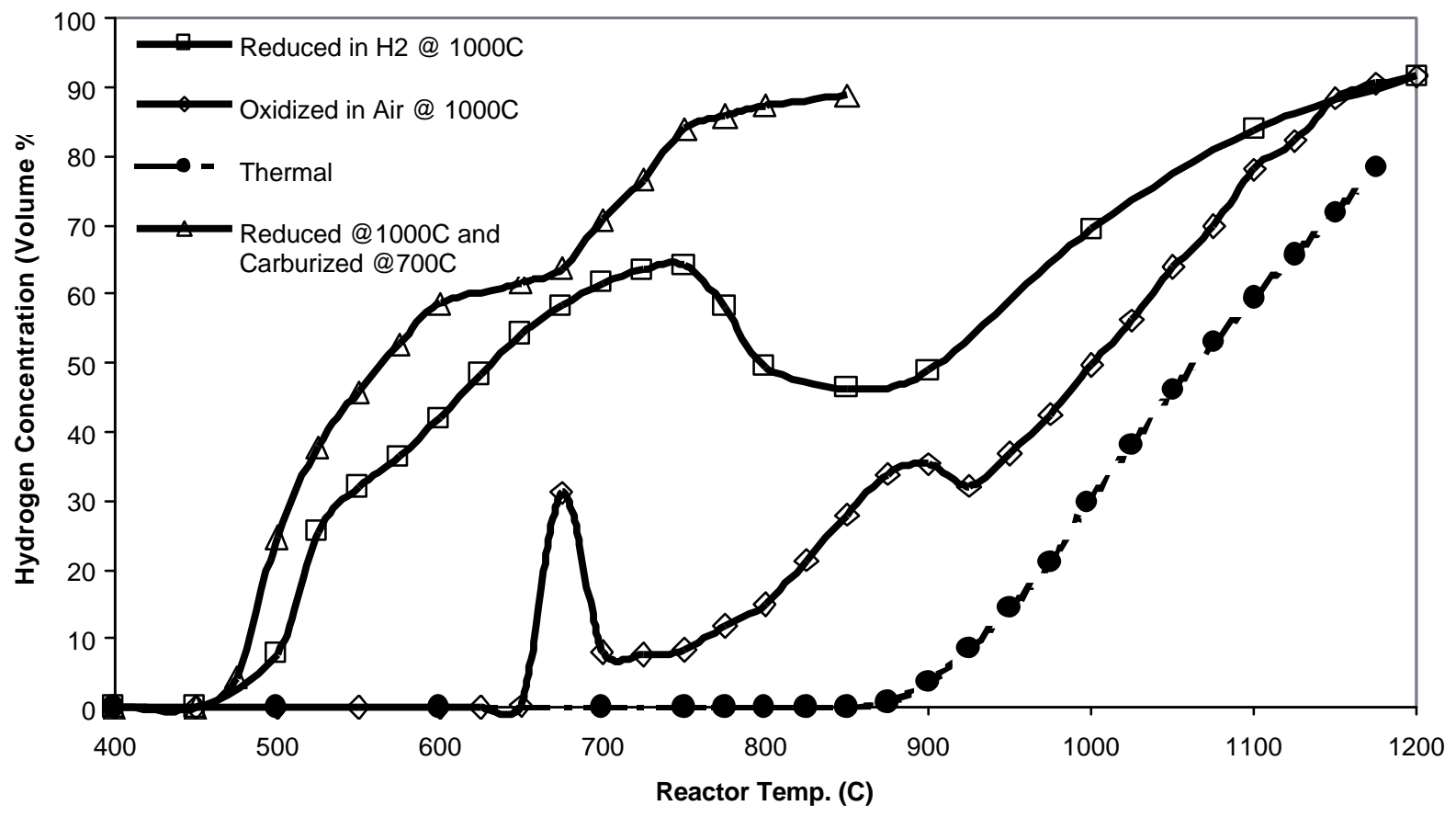

Figure 2: Effect of different pretreatments on catalytic methane decomposition using $5 \% \mathrm{Fe} / a$ lumina catalysts.

Figure 2 shows the effect of different pretreatments of $5 \% \mathrm{Fe} /$ alumina catalysts on the methane cracking reaction. For clarity, only hydrogen concentrations are plotted. The product gas stream did not contain any appreciable amounts of $\mathrm{C}_{2}$ and higher hydrocarbons. Since both hydrogen and methane are measured independently, we were able to show that the product stream contains more than $98 \%$ of only these two gases and the quantities of these two gases are complimentary $\left(\mathrm{CH}_{4} \sim 100-\% \mathrm{H}_{2}\right)$. Except in the case of non-catalytic (thermal) cracking, there was complete absence of any liquid products in all experiments. 
Oxidized $\mathrm{Fe}$ is not an active catalyst. However, under reaction conditions, it may be converting to metallic/carbide state, resulting in some activity. Reduction at $1000{ }^{\circ} \mathrm{C}$ converts the iron to a metallic state, while reduction at $1000{ }^{\circ} \mathrm{C}$ followed by carburization leaves the iron in a carbide state. The activities of the metallic and carbide phases are comparable over much of the temperature range covered. This may be due to rapid conversion of the metallic phase to the carbide phase under reaction conditions. That is, the catalyst state may end up being the same in both reaction experiments, even though they were pre-treated to produce different states. However, the pre-carburized catalyst produced much more carbon and the experiment had to be stopped due to reactor clogging at temperatures above $850 \mathrm{C}$.

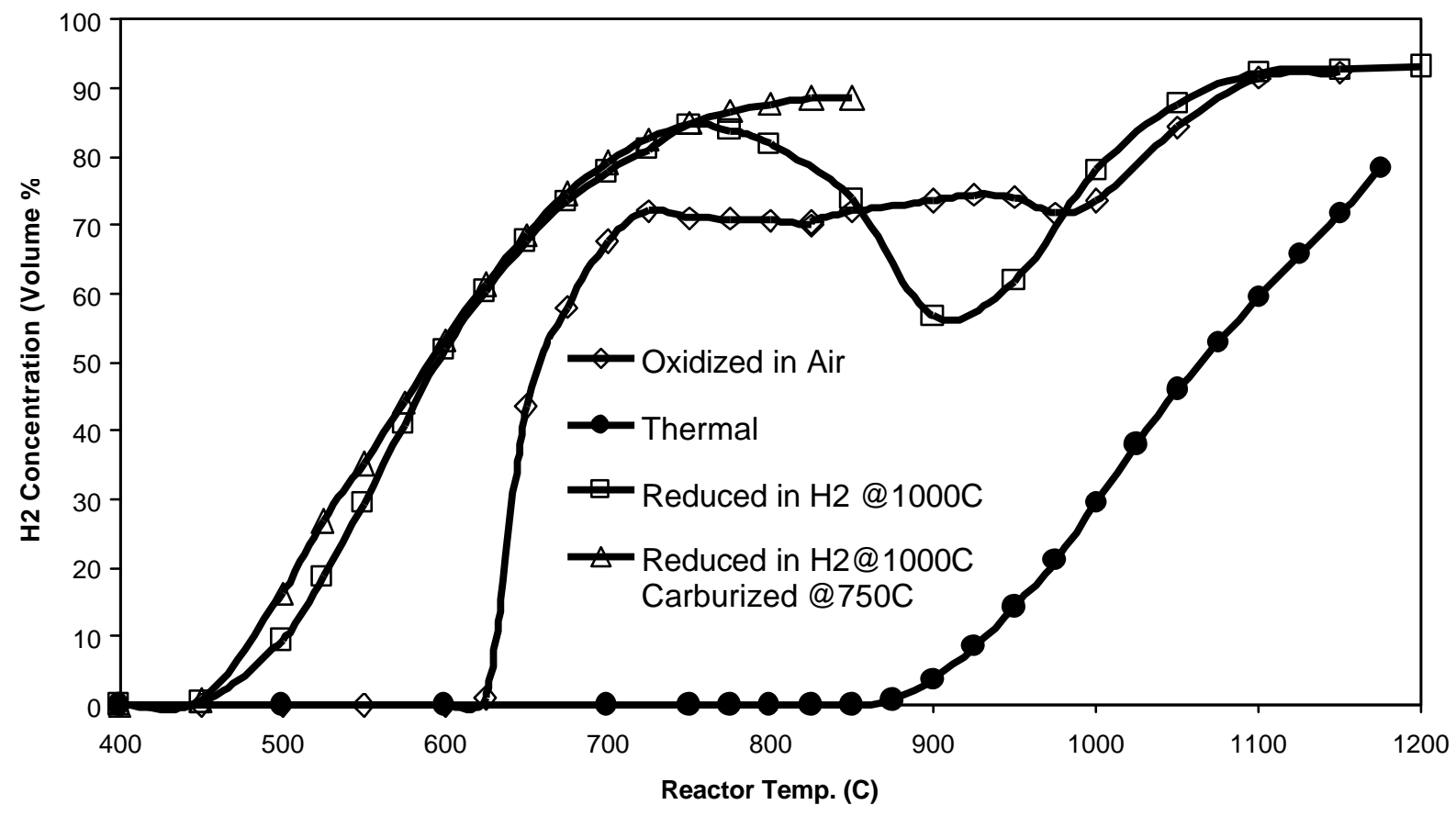

Figure 3: Effect of different pretreatments on catalytic methane decomposition using $0.5 \% \mathrm{Mo}-4.5 \% \mathrm{Fe} /$ alumin catalysts.

A $5 \% \mathrm{Mo} / \mathrm{Al}_{2} \mathrm{O}_{3}$ catalyst exhibited very little activity for methane decomposition, regardless of pre-treatment. However, the $0.5 \% \mathrm{Mo}-4.5 \% \mathrm{Fe} / \mathrm{Al}_{2} \mathrm{O}_{3}$ catalysts (figure 3 ) showed better activity than either the $5 \% \mathrm{Fe} / \mathrm{Al}_{2} \mathrm{O}_{3}$ or $5 \% \mathrm{Mo}_{2} \mathrm{Al}_{2} \mathrm{O}_{3}$ catalysts after all of the pretreatments (oxidized, reduced or carburized). All forms (oxidized, reduced and reduced/carburized) of $0.5 \% \mathrm{Pd}-4.5 \% \mathrm{Fe} / \mathrm{Al}_{2} \mathrm{O}_{3}$ catalysts also exhibited very good activity for methane decomposition. 
Figure 4 compares the observed $\mathrm{H}_{2}$ concentrations as a function of increasing temperature for all of the different catalysts after a reduction pre-treatment in $\mathrm{H}_{2}$ at $700{ }^{\circ} \mathrm{C}$. It is clear that the catalysts have a profound effect in lowering the temperature for methane cracking as compared to thermal cracking over an alumina support with no added metal catalyst. Both the bimetallic $0.5 \% \mathrm{Pd}-4.5 \% \mathrm{Fe} / \mathrm{Al}_{2} \mathrm{O}_{3}$ and the $0.5 \% \mathrm{Mo}-4.5 \% \mathrm{Fe} / \mathrm{Al}_{2} \mathrm{O}_{3}$ catalysts lower the methane decomposition temperatures by over $400{ }^{\circ} \mathrm{C}$. The mono atomic $\left(5 \% \mathrm{Fe} / \mathrm{Al}_{2} \mathrm{O}_{3}\right.$ or $\left.5 \% \mathrm{Mo}_{/} \mathrm{Al}_{2} \mathrm{O}_{3}\right)$ catalysts show much less activity than the bi-metallic $\left(0.5 \% \mathrm{Mo}-4.5 \% \mathrm{Fe} / \mathrm{Al}_{2} \mathrm{O}_{3}\right.$ or $0.5 \% \mathrm{Pd}-$ $4.5 \% \mathrm{Fe} / \mathrm{Al}_{2} \mathrm{O}_{3}$ ) catalysts reduced at $700{ }^{\circ} \mathrm{C}$. The $0.5 \% \mathrm{Pd} / \mathrm{Al}_{2} \mathrm{O}_{3}$ catalyst shows better activity than either the $5 \% \mathrm{Fe}_{\mathrm{Al}} \mathrm{O}_{3}$ or $5 \% \mathrm{Mo} / \mathrm{Al}_{2} \mathrm{O}_{3}$ catalysts, but it is still quite inferior to the bimetallic catalysts.

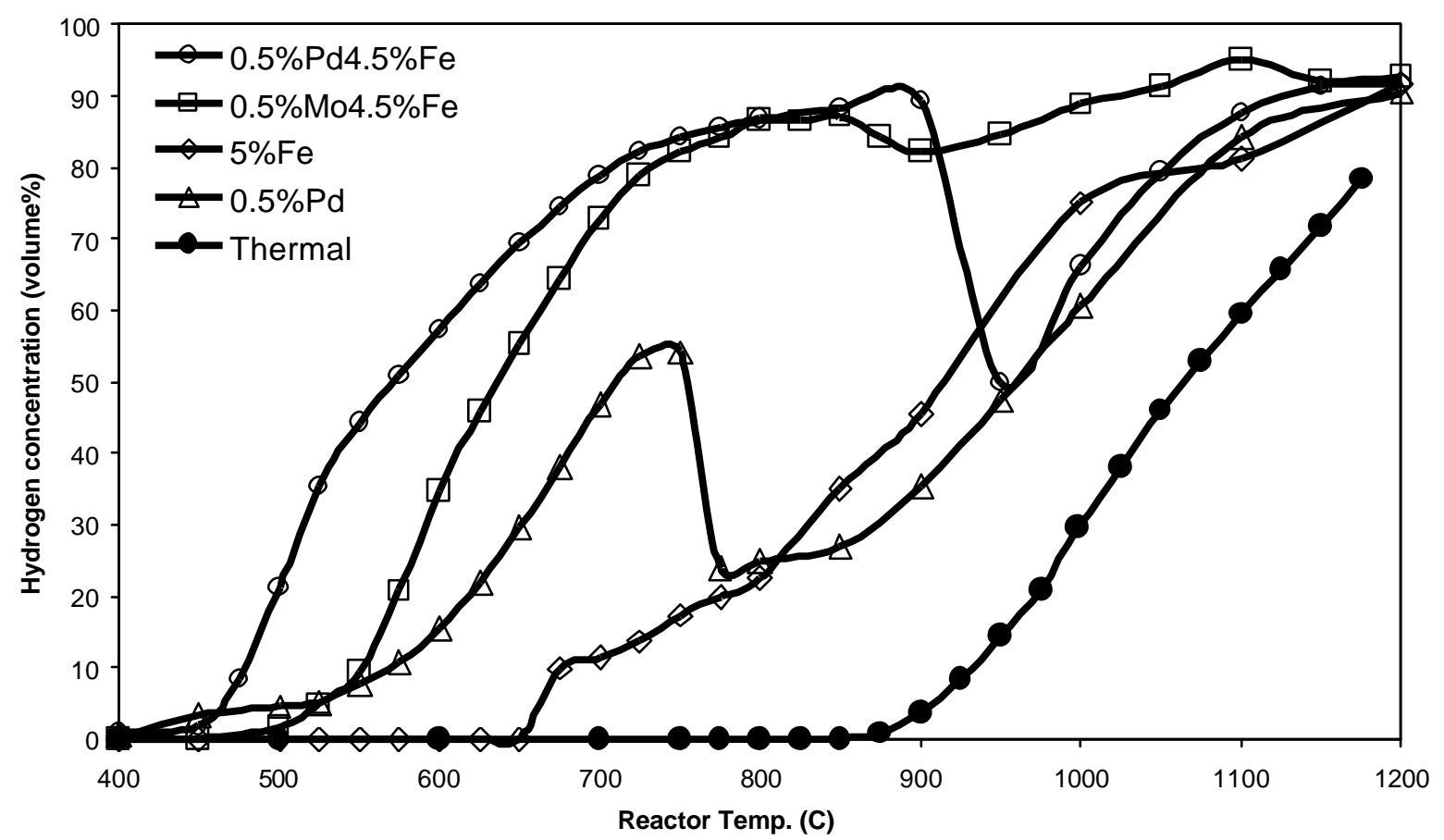

Figure 4: Effect of different metals on catalytic methane decomposition. All catalysts were prereduced in hydrogen at $700 \mathrm{C}$.

One of the problems encountered in catalytic methane decomposition is deactivation of the catalyst by carbon deposition. Using an oxidizing medium in a subsequent step, one can remove the carbon and regenerate the catalyst. Initially, we have been able to regenerate catalysts using air as an oxidizing medium. However, the product stream during air-oxidation 
step contains a large amount of nitrogen, which needs to be separated out if one wants to use CO, a valuable chemical. We have successfully regenerated the catalysts by reacting them with a stream of $\mathrm{CO}_{2}$ to produce a pure stream of $\mathrm{CO}$ at a regeneration temperature of about $1000{ }^{\circ} \mathrm{C}$.

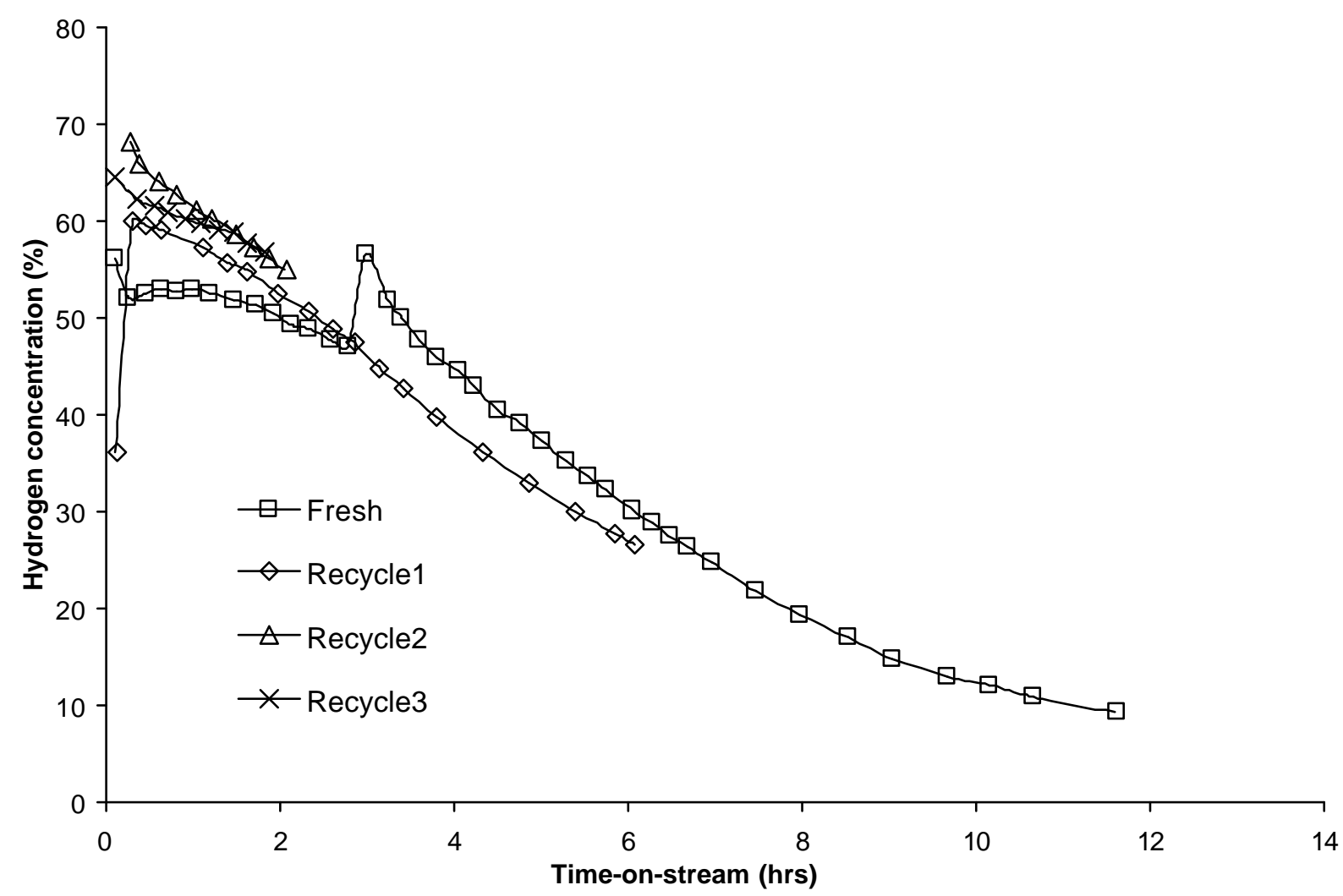

Figure 5: Deactivation of the reduced $0.5 \% \mathrm{Mo}-4.5 \% \mathrm{Fe} / \mathrm{alumina}$ catalyst due to carbon build-up on the catalyst surface at a reaction temperature of $700{ }^{\circ} \mathrm{C}$. Catalysts are regenerated by oxidizing away the carbon with $\mathrm{CO}_{2}$ at $1000{ }^{\circ} \mathrm{C}$ and by reducing in $\mathrm{H}_{2}$ at $700{ }^{\circ} \mathrm{C}$.

Figure 5 reveals the strong influence of time-on-stream and regeneration cycles on the catalytic activity of the $0.5 \% \mathrm{Mo} 4.5 \% \mathrm{Fe} / \mathrm{Al}_{2} \mathrm{O}_{3}$ catalyst. The catalysts are clearly deactivated by carbon deposition with increasing time-on-stream. The deactivated catalysts were fully regenerated by oxidation in $\mathrm{CO}_{2}$ at $1000^{\circ} \mathrm{C}$, which produces a valuable stream of pure $\mathrm{CO}$, followed by reduction of the catalyst at $700{ }^{\circ} \mathrm{C}$ in hydrogen for two hours. The regenerated catalyst exhibits activity for methane decomposition that is approximately the same as or even slightly improved over that of the fresh catalyst. After three regenerations, the catalyst showed no signs of irreversible deactivation. 
Examination of the carbon deposits by electron microscopy has established that the majority of the carbon exists in the form of carbon nanotubes. Consequently, the carbon deposits could be a high-value byproduct of the process.

In conclusion, we have demonstrated that alumina supported binary Fe-Pd and Fe-Mo catalysts are active for catalytic decomposition of methane to give a pure hydrogen stream and a potentially valuable carbon nanotubes byproduct. Reduced activity of these catalysts due to carbon deposition can be recovered by an oxidative regeneration step, which if done with $\mathrm{CO}_{2}$, yields a rather pure $\mathrm{CO}$ stream. More detailed discussion of these results will be presented and at the $221^{\text {st }}$ ACS National Meeting at San Diego (April $1-$ April 5, 2001) and at the $17^{\text {th }}$ North American Catalysis Society Meeting at Toronto, Canada (June 3 - June 8, 2001). 


\title{
In Situ Catalyst Characterization by XAFS Spectroscopy
}

\author{
N. Shah, S. Pattanaik, F.E. Huggins, and G.P. Huffman, University of Kentucky
}

A major problem in determining catalytic reaction mechanisms is assessing the state of the catalyst during the reaction and relating that to the product distribution. While measurements of catalyst structure before and after reaction often provide significant insight, the most active metal-based catalysts often have an extremely fine particle size distribution and undergo spontaneous oxidation when they are removed from the reactor and exposed to air prior to examination. In the current research, emphasis will be placed on in situ analysis of catalyst structure during pretreatment, reaction, and regeneration.

A novel in situ XAFS cell optimized for investigation of $\mathrm{Cl}$ chemistry processes has been built and tested. We have obtained safety approvals to carry out in situ XAFS experiments at the National Synchrotron Light Source (NSLS) at Brookhaven National Laboratory and have carried out some preliminary experiments there. The initial in situ XAFS experiments will focus on determining the molecular state of the Mo or Pd in the alumina supported binary Fe-Pd and FeMo catalysts during pretreatment under flowing hydrogen, during methane decomposition while carbon is being deposited, and during regeneration under flowing air. 


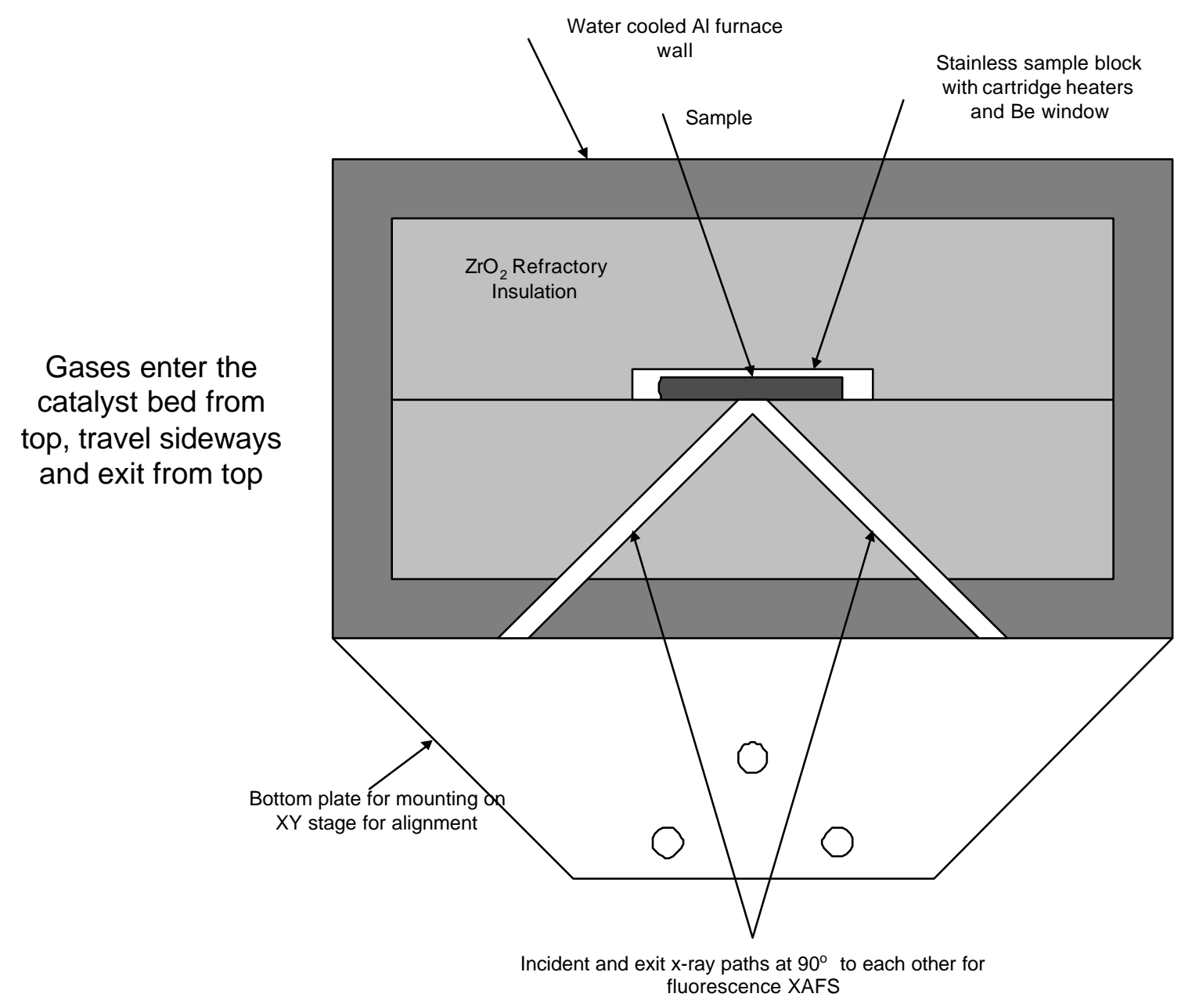




\title{
DIESEL ENGINE TESTING Of OXYGENATED FUEL ADDITIVES; PRELIMINARY TEST RESULTS
}

\author{
Henk Meuzelaar1, J acek Dworzanski', Sidney Thornton', Ted Eyring², Brian \\ Dunn $^{2}$ and Ron Pugmire ${ }^{3}$ \\ University of Utah, Center for Micro Analysis and Reaction Chemistry ${ }^{1}, 110$ S. Central \\ Campus Dr. \#214, Department of Chemistry2, Department of Chemical and Fuels \\ Engineering3
}

\section{Background}

The Utah team has been developing new catalytic processes for the synthesis of oxygenates that can be used as fuel additives in order to reduce automotive engine emissions of particulate matter (PM), volatile and semivolatile organic compounds (VOCs and SVOCs), as well as $\mathrm{NO}_{\mathrm{x}}$ without some of the environmental and health risks posed by MTBE and other highly water-soluble and/or potentially toxic oxygenates. Diethylcarbonate is one of the oxygenates with suitable physicochemical properties for which the Utah team found a promising new catalyzed synthetic route, as described by Eyring et al., elsewhere in this report.

Thus far, oxygenates appear not to have played a major role as emission-reducing diesel fuel additives. This may be partly due to the fact that the effect of oxygenates on diesel engine performance is largely unknown. On theoretical grounds it could be argued that oxygen-rich organic fuel additives are generally likely to make diesel fuel less reactive, thereby potentially contributing to less efficient combustion and, thus, emission of larger quantities of products of incomplete combustion (PICs). However, some fuel additives known to increase diesel fuel reactivity, e.g. organic nitrates, have less desirable environmental characteristics.

Therefore, we decided to set up a dedicated, small diesel engine that would allow us to test moderate quantities of well-defined diesel fuel blends and fuel additives with regard 
to their effect on PICs such as SVOCs and soot particles, as well as their effect on engine performance under realistic operating conditions.

\section{Experimental}

Table 1 lists the main characteristics of the 2- cylinder, 6kW (Kubota model Z482-B) test engine and its Land and Sea 9" water brake dynamometer. This little diesel engine was chosen to be as representative of the much larger diesel engines installed in most trucks as possible, whereas the dynamometer was selected to allow computer-controlled execution of standardized Federal Test Procedures with various engine load profiles.

A series of preliminary engine tests was performed under "idle" (@ $1600 \mathrm{rpm}$ ) and "load" (10 ft.lb torque @ 1600 rpm) conditions using a randomly purchased, street quality (local gas station in Salt Lake City) diesel fuel sample, with or without 2 ut\% (fuel oxygen) DEC or ethanol (EtOH) additive. During these tests $\mathrm{PM}_{10}$ (particulate matter $<10$ um diameter) was sampled with a high flow (29 cu ft/min) quartz fiber filter-sampling device while volatiles passing through the filter were trapped with a Tenax-filled absorption cartridge.

VOCs and SVOCs adsorbed on the cartridges, as well as on the soot particles trapped by the quartz fiber filter (or the filter itself) were analyzed by means of rapid Thermal Desorption - Gas Chromatography / Mass Spectrometry (TD-GC/MS) techniques developed at the University of Utah Center for Micro Analysis and Reaction Chemistry. 


\begin{tabular}{|l|l|}
\hline \multicolumn{2}{|c|}{ Specifications } \\
\hline $\begin{array}{l}\text { KUBOTA engine } \\
\text { model Z482-B }\end{array}$ & $\begin{array}{l}\text { LAND and SEA 9 in. } \\
\text { water brake Dynamometer }\end{array}$ \\
\hline 2- cylinder & torque load control \\
\hline 29.23 cubic inch displacement & speed control \\
\hline 800 rpm unloaded low idle speed & computer data acquisition and control \\
\hline 3800 rpm him idle speed & load absorption through entire torque range \\
\hline 0.8-2.2 L/ hr fuel consumption & $\begin{array}{l}\text { computer programmable load cycles } \\
\text { conforming to standardized Federal Test } \\
\text { Procedures }\end{array}$ \\
\hline $\begin{array}{l}\text { 2 cubic meter/ minute exhaust } \\
\text { production }\end{array}$ & \\
\hline
\end{tabular}

\section{Results and Discussion}

Preliminary test results using data from diesel engine runs under steady-state idling as well as load conditions, i.e. without an attempt to simulate more realistic driving conditions by using dynamic load profiles, strongly suggest that both oxygenates (i.e. DEC and EtOH) do have a markedly beneficial effect on VOC and SVOC emission levels, which appear to be reduced by 25-50\% (see figs. 1-3). Moreover, the much lighter color of the filters (not shown here) after oxygenated fuel runs, compared to similar runs with neat fuel, indicates that total soot particulate emission levels are also substantially reduced.

Overall, at a 2 wt\% total fuel oxygen level EtOH addition would seem to have a more pronounced effect on VOC and SVOC emission reduction than DEC. However, in view of it's relatively high volatility EtOH is generally not considered to be a practical additive for diesel fuel, whereas lower boiling homologs, such as C4-C6 alcohols have much 
lower oxygen content. Also, because of its much lower MW and somewhat lower oxygen content almost three times more EtOH than DEC molecules need to be present for a given volume of fuel to achieve the same wt\% of oxygen. Therefore a comparison between the effectiveness of "equal levels" of EtOH and DEC as diesel fuel additives strongly depends on the definitions used.

Although both aliphatic and aromatic SVOC emission levels are reduced, PNAH emissions appear to be more strongly reduced under load than when idling. In fact, some $\mathrm{PAH}$ compounds (e.g. alkyl substituted phenanthrenes) absorbed to the $\mathrm{PM}_{10}$ fraction and/or the filter are found to increase when idling with oxygenated fuel (fig. 3a), possibly reflecting lower combustion zone temperatures.

Before farther-reaching conclusions can be drawn, however, a systematic test program designed to elucidate the effects of differences in fuel mixtures, additives and operating conditions (including dynamic load profiles) will need to be carried out.

Encouraged by the results from these preliminary runs, the Utah team is now in the process of moving the diesel engine test system to a larger facility where we intend to interface additional routine emission monitoring equipment, e.g. $\mathrm{NO}_{\mathrm{x}}, \mathrm{SO}_{\mathrm{x}}$ and $\mathrm{CO}$ analyzers, as well as advanced emission characterization equipment, including exhaust dilution chambers with an attached nanoscale PM distribution counter, a PAS2000 analyzer and a specially developed repetitive sampling GC/ MS system for on-line VOC and SVOC speciation and profiling. 


\title{
ANALYTICAL CHARACTERIZATION OF CATALYST STRUCTURE AND PRODUCT DISTRIBUTION
}

\author{
M. S. Seehra and Alex Punnoose, West Virginia University \\ Project Report for the Period May 1, 2000 to October 30, 2000
}

\section{A. OBJECTIVES}

Determination of reaction mechanisms in a catalytic reaction requires understanding the electronic and structural properties of the catalyst during the reaction and their relationships to the product distribution. To that end, our work involves in-situ and ex-situ investigations of a number of catalysts employing the techniques of $\mathrm{x}$-ray diffraction (XRD), electron spin resonance (ESR) spectroscopy, magnetometry and photoacoustic/FTIR spectroscopy. We are working with three research groups (Huffman at Kentucky, Wender at Pittsburgh, and Eyring at Utah) to obtain the relevant samples of catalysts and to coordinate our results with their product distribution. A brief summary of recent results follows.

\section{B. SUMMARY OF RESULTS}

\section{1. $\mathrm{Pt} / \mathrm{WO}_{\mathrm{x}} / \mathrm{ZrO}_{2}$ catalysts:}

Wender et al have used these catalysts for the hydroisomerization of long chain linear alkanes (Task 6). Our goal has been to determine the roles and properties of the three constituents of these PWZ catalysts viz. Pt, $\mathrm{WO}_{\mathrm{x}}$ and $\mathrm{ZrO}_{2}$ and interactions among these constituents under reaction conditions. We have investigated six samples of these catalysts with W loadings between 6.5 and $12.5 \mathrm{wt} . \%$ and Pt loadings of 0.5 wt. \%. Our systematic studies using $\mathrm{XRD}$ measurements to $1000^{\circ} \mathrm{C}$ have provided the first clear evidence that the highly dispersed $\mathrm{WO}_{\mathrm{x}}$ species are supported on the tetragonal (t) phase of $\mathrm{ZrO}_{2}$ rather than monoclinic $(\mathrm{m}) \mathrm{ZrO}_{2}$. Representative data presented in Fig. 1 for the PWZ6 catalyst with 12.5 wt.\% W shows the gradual emergence of the peaks of crystalline $\mathrm{WO}_{3}$ (marked 1) and $\mathrm{m}_{\mathrm{ZrO}}$ (marked 2) at the expense of $\mathrm{ZZrO}_{2}$ (marked 3) at the higher annealing temperatures. These results show 
the close association of the dispersed $\mathrm{WO}_{3}$ (which is important for catalysis but not seen in $\mathrm{XRD}$ ) and $\mathrm{t}-\mathrm{ZrO}_{2}$. Details of these results are available in a revised paper submitted to the Journal of Catalysis [1].

The electronic state of $\mathrm{Pt}$ in these catalysts has been controversial partly because the $0.5 \%$ loading of $\mathrm{Pt}$ is too small to be detected by the standard techniques such as XRD and FTIR or Raman spectroscopies. However by careful studies of the temperature variations of the magnetic susceptibility $(\chi)$ of the PWZ catalysts and the related compounds such as $\mathrm{Pt}, \mathrm{PtO}_{2}, \mathrm{Pt}_{3} \mathrm{O}_{4}$, $\mathrm{ZrO}_{2}$ and $\mathrm{WO}_{3}$, we are able to determine the electronic state of $\mathrm{Pt}$ in these catalysts (Fig.2). This has been possible because the magnetic susceptibility of $\mathrm{Pt}, \mathrm{WO}_{3}$ and $\mathrm{ZrO}_{2}$ is relatively small, with no significant temperature dependence whereas $\chi$ for $\mathrm{PtO}_{2}$ and $\mathrm{Pt}_{3} \mathrm{O}_{4}$ are larger by nearly an order of magnitude, with very characteristic temperature dependence (Fig. 2). From these studies, we have shown that $\mathrm{Pt}$ in the as-prepared catalysts is primarily in the oxidized form, $\alpha-\mathrm{PtO}_{2}$ and/or $\mathrm{Pt}_{3} \mathrm{O}_{4}$, with their relative magnitudes dependent on the preparation procedures, thermal treatments and aging. The oxides are

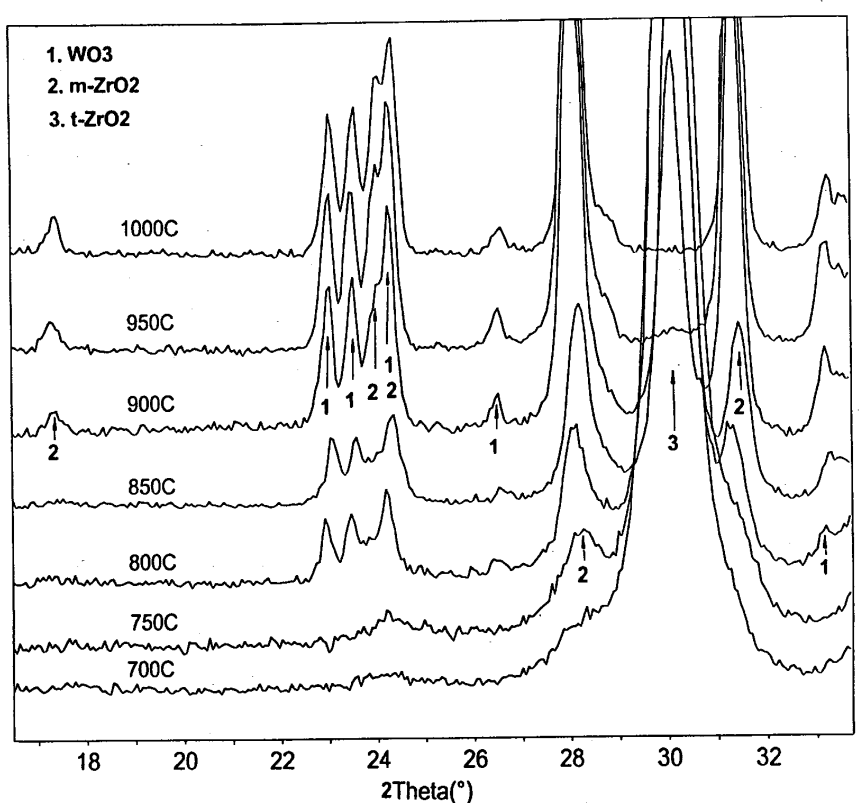

ig. 1: XRD patterns of PWZ6 (12.5 wt\% W) showing the gradual emergence of the peaks of $\mathrm{WO}_{3}$ (marked 1) and $\mathrm{m}-\mathrm{ZrO}_{2}$ (marked 2) at the expense of $\mathrm{t}-\mathrm{ZrO}_{2}$ peaks(marked 3 ) at higher annealing temperatures.

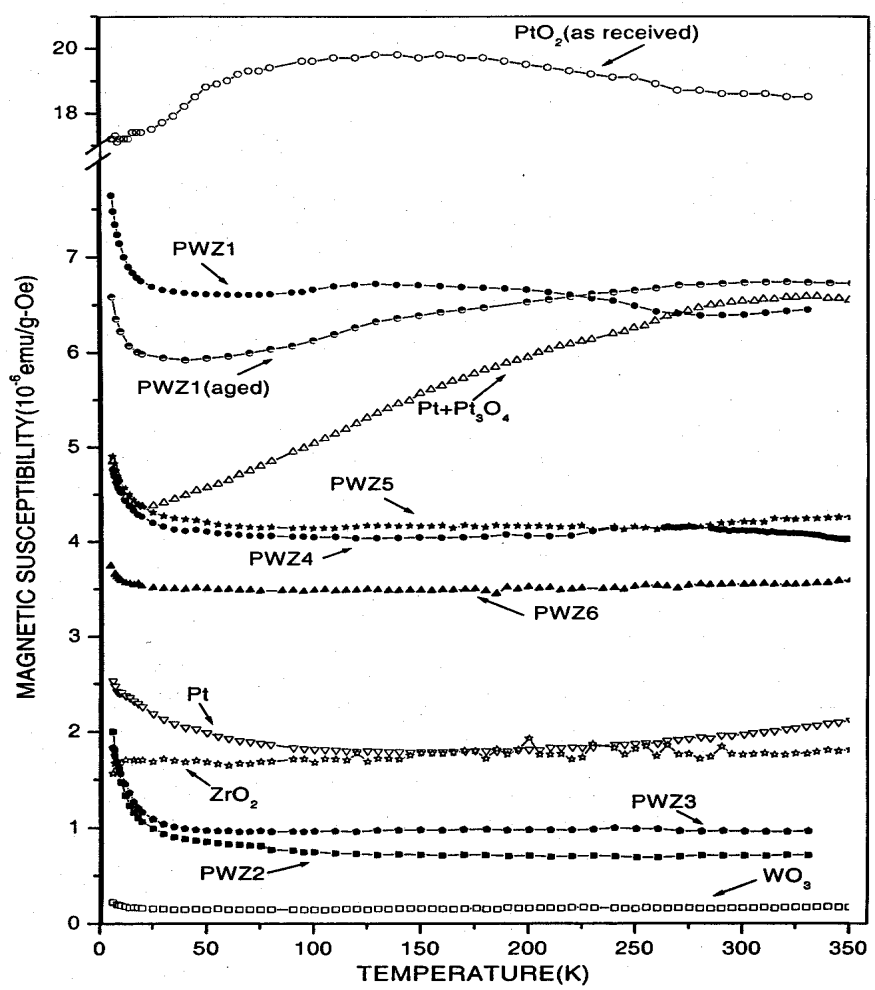

Fig. 2: Temperature variation of the magnetic susceptibility of the $\mathrm{PWZ}$ catalysts and related compounds $\left(\mathrm{Pt} \mathrm{PtO}_{2}, \mathrm{Pt}_{3} \mathrm{O}_{4}, \mathrm{ZrO}_{2}\right.$ and $\mathrm{WO}_{3}$ ). 
converted to $\mathrm{Pt}$ in reducing atmospheres and at temperatures above $800^{\circ} \mathrm{C}$. Details are given in Ref. 1.

\section{2. $\mathrm{CuCl}_{2} / \mathrm{PdCl}_{2} / \mathrm{Carbon}$ Catalysts:}

Eyring et al at Utah are investigating the synthesis of dialkyl carbonates from alcohols (Task 5) using $\quad \mathrm{CuCh}_{2} / \mathrm{PdCl}_{2}$ catalysts supported on activated carbon. We have obtained about a dozen samples of these catalysts with different $\mathrm{CuCl}_{2}$ loadings and the catalysts pretreated with $\mathrm{KOH}$ which have shown higher selectivity for diethyl carbonate. XRD and FTIR studies of these samples show no distinct features of crystalline components suggesting that $\mathrm{CuCh} / \mathrm{PdCl}_{2}$ loadings are in a highly dispersed (amorphous) form. This is confirmed by magnetometry. The most illuminating technique for the investigations of these systems is variable

temperature ESR spectroscopy where we have observed distinct lines and hyperfine structure from $\mathrm{Cu}^{2+}$ species(Fig. 3) whose parameters (intensity, linewidth) vary as $\mathrm{Cu}$ loadings are varied. The width of the sharp line shown in Fig. 3 varies systematically with $\mathrm{Cu}$ loading, in exactly the same fashion as the conversion activity for diethyl carbonate (Fig. 4). We are now in the process of accurately measuring the

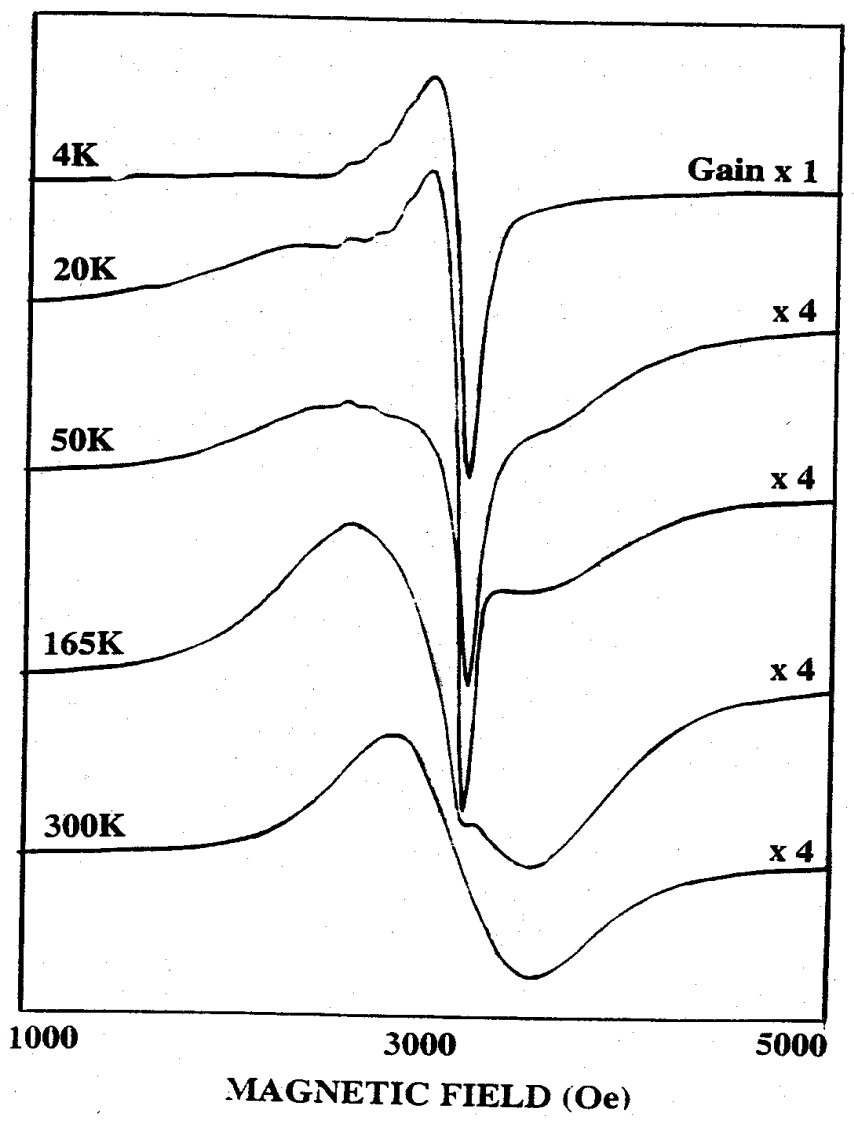

Fig. 3: ESR spectra of $8 \mathrm{wt} \% \mathrm{CuCl}_{2} / 0.4 \mathrm{wt} \% \mathrm{PdCl}_{2} / \mathrm{Carbon}$ ( catalyst at different temperatures

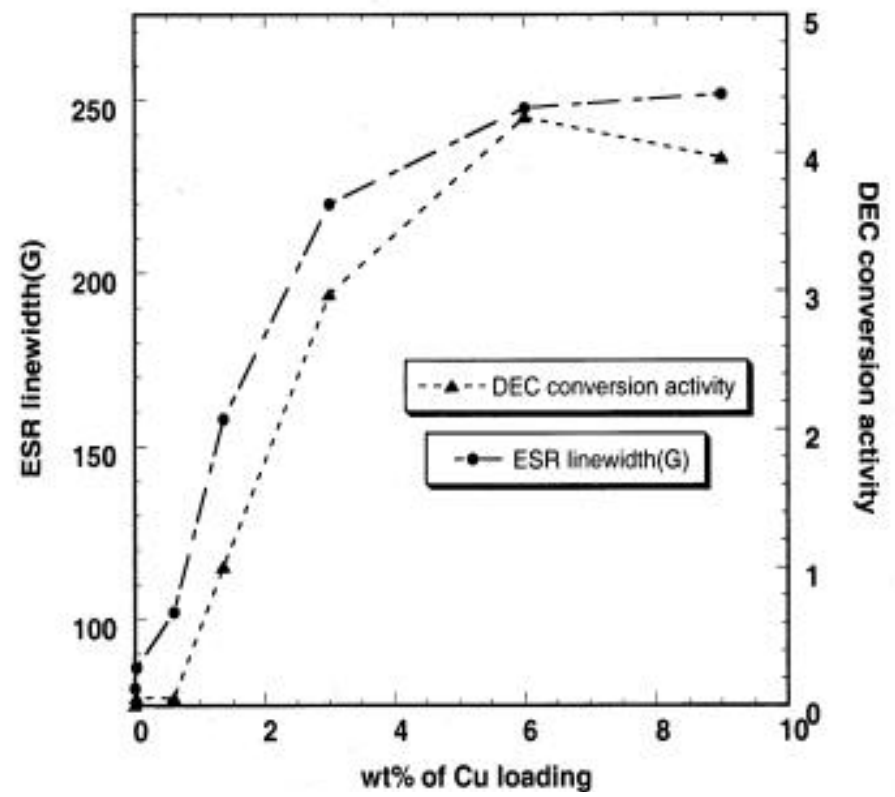

Fig. 4: Correlation between ESR linewidth and DEC conversion activity $(\%)$ of $\mathrm{CuCl}_{2} /$ Carbon catalysts with different $\mathrm{Cu}$ loadings. 
intensity of these lines to develop further correlation. The initial indications are that catalytic activity is due to $\mathrm{Cu}^{2+}$. However, the practical question of why the activity and ESR linewidth saturate at about 6\% loadings (Fig.4) may be resolved with additional measurements now in progress and analysis of these data. These results are being prepared for publication in collaboration with Eyring et.al.

\section{Doped Ferrihydrites}

Nanoparticles (? $4 \mathrm{~nm})$ of ferrihydrites, $(\mathrm{FeOOH}) \cdot \mathrm{nH}_{2} \mathrm{O}$ doped with $\mathrm{Si}, \mathrm{Al}, \mathrm{Ni}, \mathrm{Mo}, \mathrm{Ir}$ and transition metals supported on alumina are being tested by Huffman et al at Kentucky as catalysts for reforming reactions (Task 6). We are investigating the electronic properties of these catalysts by magnetometry and ESR spectroscopy, their structural properties by FTIR spectroscopy and x-ray diffraction, and their thermal stability by thermogravimetric analysis (TGA).

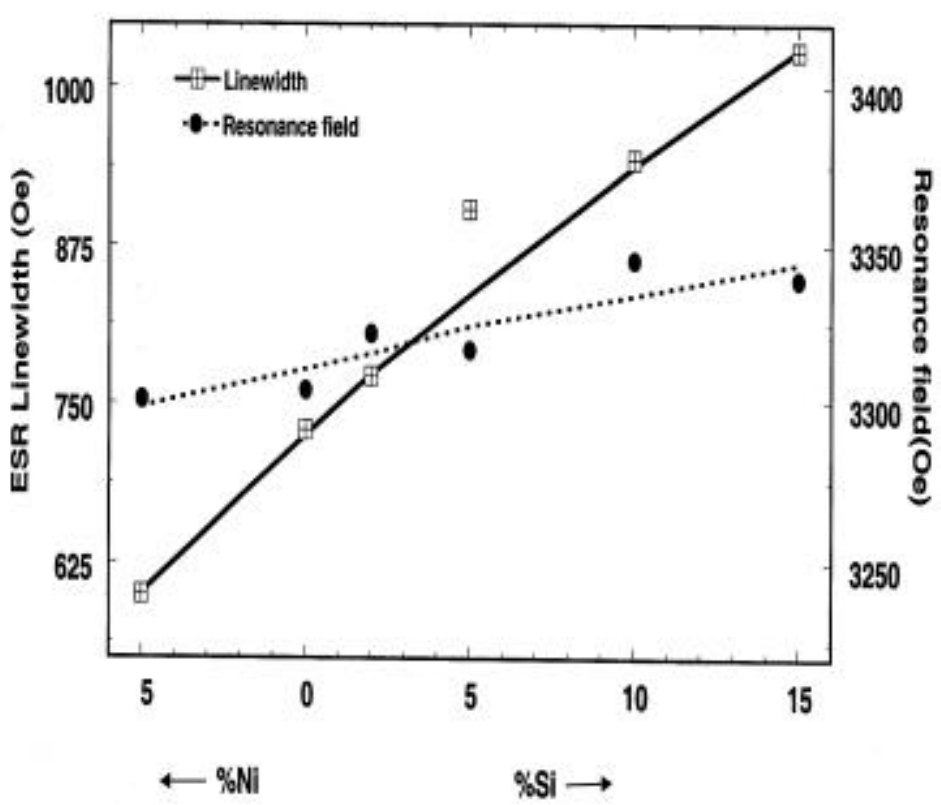

ESR and magnetic investigations in doped ferrihydrites lead us to conclude that $\mathrm{Fe}^{3+}$ spins on the surface of the nanoparticles are nearly free electron like. Doping by $\mathrm{Si}$ and $\mathrm{Ni}$ appear to replace the surface $\mathrm{Fe}^{3+}$ spins preferentially although effects of $\mathrm{Ni}$ doping are opposite to that of $\mathrm{Si}$ doping (see Fig. 5). As Si doping is increased, both the ESR lnewidth and the resonance field increase, whereas with $\mathrm{Ni}$ doping, there are decreases in the linewidth and the resonance field (Fig. 5). Most likely, these observations are related to the fact that $\mathrm{Ni}$ is magnetic and $\mathrm{Si}$ is not [2]. Doping with Mo, Ir and Al, which are also non-magnetic, has similar changes in the ESR parameters as observed for $\mathrm{Si}$, although the magnitudes of the changes are somewhat different. It will be extremely interesting to compare the catalytic efficiencies of these catalysts with the results obtained from our ESR and magnetic investigations. 
Recently we have also investigated the IR spectra of the doped ferrihydrites using our new photoacoustic/FTIR spectrometer. In Photoacoustic spectroscopy (PAS), the spectra

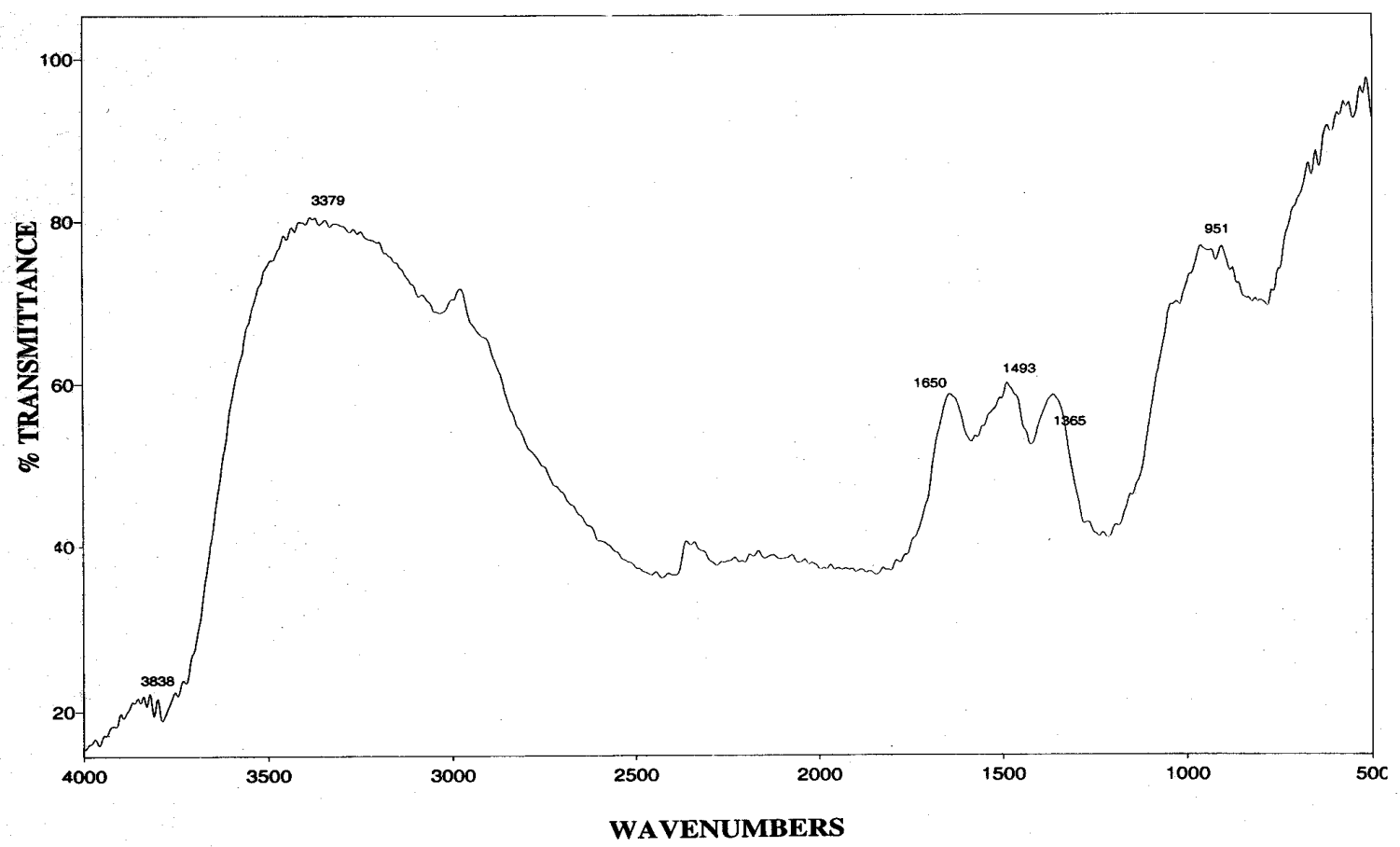

Fig. 6: PAS plot of the $10 \%$ Si doped ferrihydrite sample.

can be

measured on powder samples without mixing with $\mathrm{KBr}$ and making a pellet, so that contaminations can be avoided. In Fig. 6, we show the PAS plot for the ferrihydrite sample doped with $10 \% \mathrm{Si}$. The peaks at $951 \mathrm{~cm}^{-1}$ and $3838 \mathrm{~cm}^{-1}$ have been identified with the surface silanol group $\mathrm{SiO}-\mathrm{H}$. Intensity of these bands changes as the concentration of $\mathrm{Si}$ is changed and these bands are not observed in undoped ferrihydrite. The three bands in the $1300-1700 \mathrm{~cm}^{-1}$ range are most likely due to $\mathrm{Fe}-\mathrm{O}$ and $\mathrm{Fe}-\mathrm{OH}$ groups, while the broad band near $3379 \mathrm{~cm}^{-1}$ is due to hydrogen bonded surface $\mathrm{OH}$ groups, physisorbed water and other impurities on the surface. Both the decrease in the magnetization with $\mathrm{Si}$ doping and the appearance of the bands due to $\mathrm{Si}$ $\mathrm{O}-\mathrm{H}$ can be explained only $\mathrm{f} \mathrm{Si} \mathrm{replaces} \mathrm{Fe} \mathrm{atoms.} \mathrm{This} \mathrm{is} \mathrm{an} \mathrm{important} \mathrm{result.} \mathrm{TGA} \mathrm{studies} \mathrm{of}$ all the doped ferrihydrites are currently underway to determine their decomposition temperatures. In x-ray diffraction of the doped ferrihydrites, systematic changes in the line positions and linewidths of the two-line pattern are observed with Si doping. Our goal is now to bring all these observations together to provide a comprehensive picture of the structural and electronic properties of the doped ferrihydrites. These results could then be compared with the 
catalytic properties of these materials, hopefully enabling us to determine the mechanisms for catalysis.

\section{Students}

During 2000, two graduate students completed their M.S. theses: Paromita Roy in May 2000 on "Magnetic Properties of Si-doped ferrihydrite nanoparticles" and Heidi Magnone in December 2000 on "Synthesis and characterization of metal oxide nanoparticles". Another student, Anu Raman, is assisting us in the FTIR and TGA studies and Monia Constantinescu recently joined the research group. Using sol-gel and electrochemical techniques, Ms. Magnone synthesized nanoparticles of $\mathrm{CuO}(6-35 \mathrm{~nm}), \mathrm{Mn}_{5} \mathrm{O}_{8}(\sim 24 \mathrm{~nm}), \mathrm{Co}_{3} \mathrm{O}_{4}(7-40 \mathrm{~nm})$ and $\mathrm{NiO}$ $(30 \mathrm{~nm})$. Catalytic properties of $\mathrm{CuO}$ for the synthesis of diethyl carbonate tested by Eyring et al, showed higher yields as compared to bulk $\mathrm{CuO}$.

\section{Future Plans:}

The PWZ catalysts did not show any noticeable ESR signal at room temperature. However, recent experiments carried out at lower temperatures show several ESR lines whose intensities decrease as temperature increases so that by room temperature, these lines are not noticeable. This is a promising development since ESR, when observed, can provide detailed information about the electronic state of the species. ESR studies in all six samples of PWZ catalysts will be carried out and the origin of these lines will be determined. The relationship of the ESR lines to $\mathrm{Pt}, \mathrm{WO}_{\mathrm{x}}$ and $\mathrm{ZrO}_{2}$ needs to be determined.

For the $\mathrm{CuCl}_{2} / \mathrm{PdCl}_{2} /$ carbon catalysts, ESR studies in catalysts pretreated with $\mathrm{KOH}$, which have shown higher yields, needs to be carried out. Also intensities of the ESR lines in carefully weighed samples need to be determined so that we can ascertain the relationship between the catalytic yield and the strength of the $\mathrm{Cu}^{2+}$ species. Dr. Alex Punnoose is carrying out all ESR experiments.

For the doped ferrihydrites, considerable amount of data has been collected on the temperature and magnetic field variation of the magnetization. The PI with assistance from Dr. Punnoose is analyzing this data. This is an important and non-trivial task; important because most catalysts are nanoparticles but non-trivial because the important question of the role of interparticle interactions is not settled. We are trying to develop a consistent theoretical model to 
explain our observations and if successful, this will constitute an important contribution in nanoparticle magnetism and hence catalysis.

\section{References/Publications:}

The cited references and publications resulting from this project are listed below:

- A. Punnoose, M.S. Seehra and I. Wender, "Structure, properties, and roles of the different consituents in $\mathrm{Pt} / \mathrm{WO}_{\mathrm{x}} / \mathrm{ZrO}_{2}$ catalysts", Revised manuscript submitted to Journal of Catalysis.

- M. S. Seehra, A. Punnoose, P. Roy, and A. Manivannan, "Effect of Si doping on the ESR properties of ferrihydrite nanoparticles", IEEE Transaction on Magnetics (accepted).

- A . Punnoose, H. Magnone and M. S. Seehra, "Synthesis and antiferromagnetism of $\mathrm{Mn}_{5} \mathrm{O}_{\mathrm{s}}$ ", IEEE Transaction on Magnetics (submitted).

- M. S. Seehra, V. S. Babu, A. Manivannan and J. W. Lynn, "Neutron scattering and magnetic studies in ferrihydrite nanoparticles”, Phys. Rev. B $\underline{61}$, 3513-3518 (2000).

- M. S. Seehra, P. Roy and A. Manivannan, "Hysteresis loop shifts in magnetic field cooled FeOOH nanoparticles, Mater. Res. Soc. Symp. Proc. 593, 365-370 (2000).

- M. S. Seehra, V. S. Babu, P. Roy and A. Manivannan, "Influence of chemisorption on the magnetism of interacting ferrihydrite nanoparticles", Cluster and Nanostructure Interfaces edited by Jena et al (World Scientific Publication, 2000) pp. 229-234.

- A. Manivannan, A. Punnoose and M. S. Seehra, "Interaction of oxygen with nanophase carbons investigated by ESR spectroscopy," Mater. Res. Soc. Symp. Proc.593, 365-370 (2000). 